Discussion Paper No. 10-077

The Heterogeneous Effects of Training Incidence and Duration on Labor Market Transitions

Bernd Fitzenberger, Aderonke Osikominu, and Marie Paul

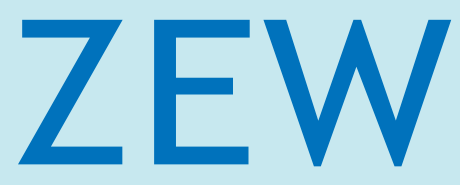

Zentrum für Europäische Wirtschaftsforschung $\mathrm{GmbH}$

Centre for European Economic Research 
Discussion Paper No. 10-077

\title{
The Heterogeneous Effects of Training Incidence and Duration on Labor Market Transitions
}

\author{
Bernd Fitzenberger, Aderonke Osikominu, \\ and Marie Paul
}

Download this ZEW Discussion Paper from our ftp server:

ftp://ftp.zew.de/pub/zew-docs/dp/dp10077.pdf

Die Discussion Papers dienen einer möglichst schnellen Verbreitung von neueren Forschungsarbeiten des ZEW. Die Beiträge liegen in alleiniger Verantwortung der Autoren und stellen nicht notwendigerweise die Meinung des ZEW dar.

Discussion Papers are intended to make results of ZEW research promptly available to other economists in order to encourage discussion and suggestions for revisions. The authors are solely responsible for the contents which do not necessarily represent the opinion of the ZEW. 


\section{Non-technical Summary}

Training programs are an important tool of active labor market policy in Germany as in many other countries. There exist different types of training programs, but also important heterogeneities within a given program type, in particular with regard to the duration of program participation. The question how the impact of a program of a certain type varies with the length of the scheme is an important dimension of program heterogeneity that has received little attention in the literature so far. One reason for this may be that actual program lengths are endogenously determined. Participants frequently drop out before reaching the planned end of the program or they stay longer on the program than originally scheduled. The decision to shorten or prolong program participation depends on the success in job search, an issue that must not be neglected when studying the effect of different program lengths. In addition, the assignment to training depends on the success of job search, because training programs in Germany may be assigned to the job-seeker at any point in time but only as long as he or she has not yet reentered employment. Furthermore, selection into program participation and employment may depend on characteristics observable to the researcher (like age and education, for example) and characteristics unobservable to the researcher (like personal traits, for example). In this paper, we propose and estimate an econometric model that takes all these issues into account. Furthermore, we develop a strategy to simulate the treatment effects of interest using our estimation results.

We study a large-scale German program involving training in professional skills (Förderung der beruflichen Weiterbildung). Participation in the program lasts eight months on average, but scheduled program lengths vary between a couple of weeks and more than one year. We use rich administrative data and perform separate estimations by gender and region (East and West Germany). Our findings imply positive effects of training on the employment probability emerging three to four quarters after program start in all four subsamples considered. First, our estimates suggest that ten quarters after program start employment rates of the participants are on average 12 to 21 percentage points higher, than they had been in the counterfactual scenario in which participants had not participated in the program. The effects are higher for women than for men and higher in West Germany than in East Germany. Second, we use our model estimates to simulate the effect of treatment 
start at a given date versus not starting a program at that point in time but maybe later. We find that this effect - the effect of participating versus waiting - is about one third lower than the effect of participating versus not participating. Third, we use our estimates to analyze how training effects vary with the planned program duration. During training, participants generally search less intensively for a new job than comparable nonparticipants. Therefore, employment effects of training are typically negative in the short run, and positive effects may unfold only some time after the completion of the program. Our analysis provides evidence to address explicitly the question whether negative short-run effects are necessary to achieve economically important positive employment effects in the long run, or whether comparable long-run effects can be obtained with shorter programs at lower costs. Our findings suggest that longer planned enrollment lengths of three and four quarters, respectively, as opposed to just two quarters lead to an increase in employment rates by four to six percentage points and six to eleven percentage points, respectively, in the medium and long run. This suggests that, on average, longer training programs translate into higher long-run employment gains. 


\section{Das Wichtigste in Kürze}

Weiterbildungsmaßnahmen sind ein wichtiger Bestandteil der Aktiven Arbeitsmarktpolitik in Deutschland und in vielen anderen Ländern. Neben verschiedenen Typen von Weiterbildungsangeboten gibt es auch bedeutende Unterschiede innerhalb eines Typs von Weiterbildung, insbesondere in Bezug auf die Dauer der Maßnahme. Die Dauer der Maßnahme ist eine wesentliche Dimension der Programmheterogenität, die bisher in der Literatur wenig untersucht wurde. Das liegt vermutlich daran, dass die Untersuchung der Effekte unterschiedlicher Programmlängen dadurch erschwert wird, dass viele Teilnehmer nicht so lange an der Maßnahme teilnehmen, wie es ursprünglich geplant war. Stattdessen brechen sie die Maßnahme ab, bevor sie das geplante Ende erreichen, oder sie nehmen länger teil als ursprünglich geplant. Die Entscheidung, die Programmteilnahme zu verkürzen oder zu verlängern, hängt vom Erfolg der Beschäftigungssuche ab - ein Problem, das bei der Untersuchung des Effekts von verschiedenen Maßnahmenlängen nicht vernachlässigt werden darf. Zusätzlich hängt auch die Zuweisung einer Weiterbildungsmaßnahme vom Erfolg bei der Beschäftigungssuche ab, denn in Deutschland können dem Arbeitslosen zu jedem Zeitpunkt Weiterbildungsmaßnahmen zugewiesen werden, allerdings nur, solange er noch nicht wieder in Beschäftigung eingetreten ist. Darüber hinaus wird die Wahrscheinlichkeit, in eine Maßnahme oder in Beschäftigung überzugehen, potenziell von in den Daten beobachtbaren Eigenschaften (wie z.B. Alter und Bildungsgrad) und von in den Daten unbeobachtbaren Eigenschaften (wie z.B. charakterliche Eigenschaften) beeinflusst. In der vorliegenden Studie schlagen wir ein ökonometrisches Modell vor, das diese Selektionsmechanismen berücksichtigt. Außerdem entwickeln wir eine Strategie, die es erlaubt, wichtige Maßnahmeneffekte auf Basis der Schätzergebnisse zu simulieren.

Wir evaluieren ein wichtiges Programm der beruflichen Weiterbildung in Deutschland (Förderung der beruflichen Weiterbildung), das berufliche Kenntnisse und Fähigkeiten vermittelt. Die Maßnahmen dauern im Durchschnitt acht Monate, aber die geplanten Dauern variieren zwischen einigen Wochen und mehr als einem Jahr. Wir verwenden reichhaltige administrative Daten und führen separate Schätzungen nach Geschlecht und Region (Ost- und Westdeutschland) durch. Für alle Untergruppen finden wir positive Effekte der Maßnahmenteilnahme auf die Beschäftigungswahrscheinlichkeit, die sich drei bis vier Quartale nach Maßnahmebeginn 
herauskristallisieren. Erstens kommen wir zu dem Ergebnis, dass zehn Quartale nach Maßnahmebeginn die Beschäftigungsraten der Teilnehmer im Schnitt 12 bis 21 Prozentpunkte höher sind, als sie ohne Teilnahme an einer Maßnahme gewesen wären. Die Effekte sind für Frauen größer als für Männer und in Westdeutschland größer als in Ostdeutschland. Zweitens verwenden wir unsere Schätzergebnisse für die Simulation des Effektes von einem Weiterbildungsbeginn zu einem bestimmten Zeitpunkt im Vergleich zu der Situation, zu diesem Zeitpunkt keine Weiterbildung zu beginnen, aber vielleicht zu einem späteren Zeitpunkt. Unser Ergebnis ist, dass dieser Effekt - also der Effekt, jetzt an einer Maßnahme teilzunehmen statt erst einmal abzuwarten, - etwa ein Drittel kleiner ist als der Effekt der Teilnahme gegenüber Nichtteilnahme. Drittens verwenden wir unsere Ergebnisse, um zu untersuchen, wie Maßnahmeneffekte sich für verschiedene geplante Maßnahmendauern unterscheiden. Während einer Maßnahme suchen Teilnehmer oftmals weniger intensiv nach einer Beschäftigung als Nichtteilnehmer. Darum ist der Beschäftigungseffekt einer Maßnahme typischerweise zunächst negativ und positive Maßnahmeneffekte entstehen erst einige Zeit nach Ende der Maßnahme. Unsere Untersuchung ermöglicht es, explizit die Frage zu untersuchen, ob kurzfristig negative Effekte notwendig sind, um langfristig ökonomisch bedeutende positive Effekte zu erreichen, oder ob vergleichbare langfristige Effekte durch kürzere Maßnahmen zu geringeren Kosten erzielt werden können. Es zeigt sich, dass eine geplante Dauer von drei bzw. vier Quartalen gegenüber einer geplanten Dauer von nur zwei Quartalen zu einer mittel- und langfristigen Erhöhung der Beschäftigungsrate von vier bis sechs bzw. sechs bis elf Prozentpunkten führt. Das Ergebnis legt nahe, dass längere Weiterbildungsmaßnahmen im Durchschnitt zu höheren langfristigen Beschäftigungsgewinnen führen. 


\title{
The Heterogeneous Effects of Training Incidence and Duration on Labor Market Transitions ${ }^{1}$
}

\author{
Bernd Fitzenberger, ${ }^{\natural}$ Aderonke Osikominu,$\sharp$ and Marie Paul ${ }^{\S}$ \\ ${ }^{b}$ Albert-Ludwigs-University Freiburg, ZEW, IZA, IFS, bernd.fitzenberger@vwl.uni-freiburg.de \\ \#Albert-Ludwigs-University Freiburg, IZA, osikominu@vwl.uni-freiburg.de

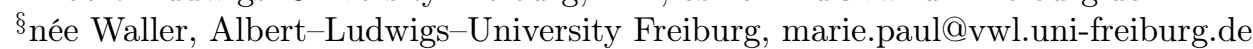

This version: October 19, 2010

\begin{abstract}
This paper estimates the impact of training incidence and duration on employment transitions accounting for the endogeneity of program participation and duration. We specify a very flexible bivariate random effects probit model for employment and training participation and we use Bayesian Markov Chain Monte Carlo (MCMC) techniques for estimation. We develop a simulation approach that uses the estimated coefficients and individual specific effects from the MCMC iterations to calculate the posterior distributions of different treatment effects of interest. Our estimation results imply positive effects of training on the employment probability of the treated, lying between 12 and 21 percentage points ten quarters after program start. The effects are higher for women than for men and higher in West Germany than in East Germany. Further, we find that the effect of training versus waiting underestimates the effect of training versus no training in the medium and long run by a third. Finally, our results show that longer planned enrolment lengths of three and four quarters as opposed to just two quarters lead to an increase in employment rates in the medium and long run by four to eleven percentage points.
\end{abstract} Keywords: evaluation, active labor market programs, dynamic non-linear panel data models, MCMC

JEL: J68, C33, C11

\section{Correspondence:}

Dept. of Economics, Albert-Ludwigs-University Freiburg, 79085 Freiburg, Germany

\footnotetext{
${ }^{1}$ This study is part of the project "Employment effects of further training programs 2000-2002 - An evaluation based on register data provided by the Institute of Employment Research, IAB ("Die Beschäftigungswirkungen der FbW-Maßnahmen 2000-2002 auf individueller Ebene - Eine Evaluation auf Basis der prozessproduzierten Daten des IAB"; IAB project number 6-531.1A). This project is joint with the Swiss Institute for International Economics and Applied Economic Research at the University of St. Gallen (SIAW) and the Institute for Employment Research (IAB). We gratefully acknowledge financial and material support by the IAB. The usual caveat applies.
} 


\section{Contents}

1 Introduction 1

2 Institutional Background and Data $\quad 6$

2.1 Training in Germany . . . . . . . . . . . . . . . . . 6

2.2 Constructing a Panel Data Set . . . . . . . . . . . . . . . . . . . . 9

2.3 Descriptive Analysis . . . . . . . . . . . . . . . . . . . . 11

3 Evaluation Framework 12

3.1 A Framework for Dynamic Treatment Effects . . . . . . . . . . . . . . 12

3.2 Implementation . . . . . . . . . . . . . . . . . . . 18

3.3 Specification . . . . . . . . . . . . . . 20

3.4 MCMC Estimation . . . . . . . . . . . . . . . . . 21

3.5 Estimation of Treatment Effects . . . . . . . . . . . . . . 23

4 Estimation Results $\quad 26$

4.1 Model Fit and Selection on Unobservables . . . . . . . . . . . . . . 26

4.2 Classical Treatment Effect on Employment and on Transition Rates . 27

4.3 Training versus Waiting . . . . . . . . . . . . . 28

4.4 Treatment Effects for Different Planned Training Durations . . . . . . 29

5 Conclusions $\quad 31$

$\begin{array}{ll}\text { References } & 32\end{array}$

$\begin{array}{ll}\text { Appendix } & 47\end{array}$

A Detailed Information on the Data 47

B Algorithm for the MCMC Estimation 48

C Detailed Estimation Results $\quad 49$ 


\section{Introduction}

With rapidly changing technologies human capital development is viewed as a key element to ensure employability of individuals in the long run. Training programs are an important tool of active labor market policy in many advanced countries (see e.g. OECD, 2007, table J). Training schemes typically comprise a wide variety of programs, from job application training to basic education and advanced vocational training taking place on the job or in classrooms. In addition, there exist important heterogeneities within a given type of training.

An important dimension of heterogeneity that has received little attention in the literature is how the impact of a given type of training program varies with the length of enrolment. ${ }^{2}$ One important reason for this is that realized training duration is an endogenous variable that depends on the success of job search during training. ${ }^{3}$ On the one hand, lucky participants who receive a suitable job offer during training may drop out early, while the unlucky ones continue until the scheduled program end or even prolong participation for lack of job opportunities. This argument suggests that dropouts are a positively selected subset of participants. On the other hand, individuals may also drop out because they are unable to follow the program (e.g. because of lack of endurance). This argument suggests a negative selection of dropouts compared to completers. In any case, program drop out for reasons that are related to employment outcomes after program start raises additional endogeneity issues that are difficult to incorporate in static evaluation approaches that are commonly used in the literature. ${ }^{4}$

Not only the decision to continue or to drop out is dynamic but also the assignment to training often depends on the success of job search. In countries with comprehensive

\footnotetext{
${ }^{2}$ Two notable exceptions are Flores-Lagunes et al. (2009) and Kluve et al. (2007). Both studies view realized training duration as a continuous treatment and use a static matching approach to evaluate the effects of different training lengths. Kluve et al. (2007) test the robustness of their results by instrumenting realized training duration with planned duration for a subsample of their data set.

${ }^{3}$ See Waller (2009) for an empirical analysis of endogenous training dropouts in Germany.

${ }^{4}$ For general surveys of evaluation studies including training see e.g. Heckman et al. (1999), Martin and Grubb (2001), Card et al. (2009). Recent evaluation studies for training programs conducted in Germany using a static approach for program assignment include e.g. Bergemann et al. (2009) and Lechner et al. (2009). In order to apply static evaluation methods, such as those suggested by Hirano and Imbens (2004) and Imai and van Dijk (2004) for continuous treatments or Imbens (2000) and Lechner (2001) for multiple discrete treatments, one would have to assume that actual enrolment length is either exogenous or determined at the same time as participation.
} 
systems of active labor market policies like Germany or Sweden (cf. Sianesi, 2004, on Sweden), participation in active labor market programs may take place at any point in time during unemployment. Eventually, every unemployed who does not manage to find a job on his own is assigned to an active labor market program. ${ }^{5}$

The main contribution of this paper is to estimate the impact of training incidence and planned training duration on employment transitions while taking into account the dynamic, endogenous nature of program participation. Furthermore, we compare the effect of training versus no training to the effect of training versus waiting that has been in the focus of the literature applying sequential matching techniques to address the issue of dynamic program starts (see e.g. Sianesi, 2004, Biewen et al., 2007, and Dyke et al., 2006). The effect of treatment versus waiting includes future participants in the control group and thus likely under- or overestimates the effect of treatment versus no treatment.

We focus on a large scale training program in Germany that lasts eight months on average and for which enrolment lengths vary between a couple of weeks and more than one year. We specify a joint model for the transition rates into and out of employment and training using a very flexible bivariate random effects probit model. Our specification allows in a flexible way for state dependence and duration dependence in the transition rates as well as in the treatment effects and it includes interaction effects of these model components with observed covariates. Our rich administrative data allow us to integrate such flexibility into the model while performing separate estimations by gender and region (East and West Germany). Estimating a discrete time model for labor market transitions, we account for the full observation vector for each individual over time, irrespective of the number of unemployment and employment spells experienced by an individual. We use Bayesian Markov Chain Monte Carlo (MCMC) techniques that allow a numerically very robust estimation of our flexible model specification. ${ }^{6}$

Another advantage of the MCMC technique is that it provides predictions of the individual specific effects. This allows us to assess explicitly the selectivity of the

\footnotetext{
${ }^{5}$ Fredriksson and Johansson (2008) present a formal analysis of the bias that results when applying a static evaluation approach in the case of a dynamic assignment regime as described above.

${ }^{6}$ See Chib (2001) for a survey on MCMC methods and for recent applications in labor economics see Buchinsky et al. (2010), Horny et al. (2009), and Troske and Voicu (2010).
} 
treated and the nontreated individuals. We develop a simulation approach that uses the estimated individual specific effects and other model parameters to calculate the posterior distributions of different treatment effects of interest, such as the average treatment effect on the treated for the employment probability. Furthermore, we use our estimation results to simulate the effects of alternative policy scenarios. In particular, we examine how the impact of training changes when assigning different planned enrolment lengths.

A comparative assessment of different enrolment lengths for the same type of training is important for policy makers interested in an efficient use of active labor market programs. Comprehensive training schemes typically range among the most expensive active labor market programs. During training, participants generally search less intensively for a new job than comparable nonparticipants (lock-in effect). Therefore, employment effects of training are typically negative in the short run, and positive effects may unfold only some time after the completion of the program. Our analysis provides evidence to address explicitly the question whether negative short-run effects are necessary to achieve economically important positive employment effects in the long run, or whether comparable long-run effects can be obtained with shorter programs at lower costs.

A prominent issue in the evaluation literature is the nonrandom sorting of individuals into training programs. Our dynamic modeling approach accounts for selection into training based on observables as well as unobservables. Our identification strategy is semiparametric. It relies on mild functional form assumptions and exploits identifying restrictions implied by the institutional setup as well as the richness of our data in terms of sample size and covariates. With respect to the unobservables, we specify a similar structure as in the frameworks suggested by Abbring and van den Berg (2003, henceforth AvdB) and Heckman and Navarro (2007, henceforth $\mathrm{HN}$ ) in which a low-dimensional set of latent variables generates the dependence across equations and across time. We allow for a rich set of observed covariates and a great flexibility in the way they enter the employment and training equations. In particular, we model state dependence and duration dependence in a very flexible way, allowing for interactions with observed covariates. We also allow for flexible heterogeneity of treatment effects with respect to observed covariates. In this respect, our approach is similar to matching analyses that rely on a rich and flexible specification of the observed heterogeneity. In contrast to matching methods, we 
allow in addition for selection into and out of training based on unobservables.

The problem of dynamic program starts has been addressed in different ways so far. In one strand of the literature, sequential matching techniques mimic a sequential randomization into treatment of individuals who are unemployed for the same elapsed duration at a given date in a sequence of possible dates. The application of matching methods presumes that sufficiently rich data are available to justify that there remains no selection on unobservables after controlling for observable variables. Identification of causal treatment effects requires that conditional on observed covariates current and future treatment status as well as future outcome states cannot be anticipated at the individual level. This approach allows one e.g. to estimate the average effect of receiving treatment at a given date of elapsed unemployment duration versus not, implying the possibility of treatment at a later time (i.e. the effect of treatment now versus waiting, Sianesi, 2004). However, as this approach focuses on nonparametric identification at given elapsed durations and does not specify a model for the selection over time, it is not possible to estimate a causal treatment effect averaged across starting dates. ${ }^{7}$

A different strand of the literature uses a continuous-time duration framework to estimate treatment effects. In contrast to sequential matching, this approach models selection into an outcome state and treatment over time. AvdB show that with single spell data on unemployment durations, waiting times until treatment start, and time constant covariates one can semiparametrically identify the effect of treatment on the exit rate from unemployment allowing for correlated individual specific effects in the outcome and the treatment equation. In particular, one has to assume a mixed proportional structure of the hazard rates into employment and into training and independence between unobservables and observables. Furthermore, identification requires that the exact moment of treatment cannot be anticipated at the individual level conditional on observed and unobserved covariates. ${ }^{8}$ AvdB

\footnotetext{
${ }^{7}$ Recent applications of this approach to the evaluation of training programs include Biewen et al. (2007) and Dyke et al. (2006).

${ }^{8} \mathrm{AvdB}$ also discuss identification based on multiple spell data where unobserved heterogeneity terms are constant within an individual. In this case, the proportionality assumption can be relaxed and observed covariates are not required any more. The baseline model of AvdB can be extended to include the effects of treatment on subsequent hazard rates or heterogeneous treatment effects that depend on observed as well as unobserved covariates. Abbring and van den Berg (2004) discuss the link between treatment effects estimation using duration models based on the timing-of-events approach on the one hand and cross-sectional binary treatment models as well as panel data models with individual specific effects on the other hand.
} 
view the durations in untreated unemployment until treatment start and until exit to employment as two competing risks which are linked through a permanent correlation of the unobserved heterogeneity terms (see Abbring and van den Berg, 2004, p. 15). Based on the proportionality and the conditional no-anticipation assumption, the treatment effect can be distinguished from the permanent correlation of the unobservables because program starts vary randomly over time across individuals conditional on observed covariates and the modeled unobserved heterogeneity. The treatment effect can be traced out by contrasting the hazard rate to employment after treatment start with the one where treatment has not yet started. ${ }^{9}$

HN consider semiparametric identification of dynamic treatment effects in reduced form and structural dynamic discrete choice models. They jointly model time to treatment and counterfactual outcomes associated with different treatment times. Similar to AvdB, the treatment status is allowed to depend on unobserved factors in the outcome equation. HN require the existence of exclusion restrictions or structural modeling assumptions allowing to vary choice indices over their full support independently of the outcomes for semiparametric identification of causal effects. In a dynamic context, one needs instrumental variation at each stage of the sequential selection process or variation in the impact of time-invariant instruments (see HN, Theorems 1 and 2). This variation must not be fully anticipated by the agents. ${ }^{10}$

Our paper contributes to and extends the dynamic evaluation literature in the following way. We implement a joint model in discrete time for transitions into and out of employment and into and out of training. We do not only take into account the endogenous timing of program starts but also the endogeneity of program duration. Our model allows for selection into training based on unobservables that are assumed to be independent of observed covariates. Similar to AvdB, our approach exploits the conditional no-anticipation assumption for identification of the causal effect of training. Similar to HN our model is specified in discrete time. We model the impact of training in a very flexible way in order to reduce the influence of functional form assumptions to a minimum. Based on our model estimates, we evaluate the causal effects of training incidence and planned duration.

\footnotetext{
${ }^{9}$ Recent applications of this approach to the evaluation of training programs include Hujer et al. (2006), Richardson and van den Berg (2008), Osikominu (2009).

${ }^{10}$ Abbring and van den Berg $(2003,2005)$ argue that it is often difficult to maintain exclusion restrictions in dynamic settings with forward-looking agents.
} 
Our main findings are as follows. We estimate positive effects of training on the employment probability unfolding three to four quarters after program start in all four subsamples considered. Ten quarters after program start, the effect of treatment on unconditional employment rates for the treated individuals lies between 12 and 21 percentage points (ppoints). The effects are higher for women than for men and higher in West Germany than in East Germany. To compare our results to the recent literature applying sequential matching estimators, we use our model estimates to simulate the effect of treatment start at a given date versus waiting (Sianesi, 2004). We find that the effect of treatment versus waiting underestimates the treatment effect of training versus no training in the medium and long run by a third. Finally, we use our estimates to analyze how training effects vary with planned program duration. Longer planned enrolment lengths of three and four quarters as opposed to just two quarters lead to an increase in employment rates by four to six ppoints and six to eleven ppoints, respectively, in the medium and long run. Thus, longer training programs show higher long-run employment gains, which may justify the higher costs involved.

The remainder of this paper is structured as follows. Section 2 describes the institutional setup and the data set used. Section 3 presents our evaluation framework and the MCMC estimation procedure. Section 4 discusses the results and section 5 concludes. The appendix provides further details on the data, the implementation of the estimation approach, and detailed estimation results.

\section{Institutional Background and Data}

\subsection{Training in Germany}

Training schemes have traditionally dominated active labor market policy in Germany. Legislation distinguishes three main types of training, further training (Berufliche Weiterbildung), retraining (Berufliche Weiterbildung mit Abschluss in einem anerkannten Ausbildungsberuf), and short-term training (Trainingsmaßnahmen und Maßnahmen der Eignungsfeststellung). Figure 1 shows the evolution of entries into the three different training programs in West and East Germany during the period 1999 to 2007. Until 2000, enrolment into further training (henceforth also referred to as long-term training) was around 260,000 in West Germany and 170,000 in East 
Germany. A policy reorientation favoring programs supposed to activate the unemployed in the short run led to a decline in further training and retraining and a sharp increase in short-term training. In 2004, participation in further training was about 100,000 in West Germany and about 50,000 in East Germany. The corresponding figures for short-term training were 800,000 and 400,000, respectively, up from around 200,000 in 1999. After a low in 2005, participation recovered somewhat in 2006 and 2007.

- Insert figure 1 about here. -

The main goal of active labor market policy in Germany is to reintegrate unemployed individuals into employment. In this study we focus on further training programs. They are used to adjust the skills of the unemployed to changing requirements of the labor market and possibly to changed individual conditions of employability (due to health problems for example). Further training courses typically last several months to one year and are usually conducted as full-time programs. Teaching takes place in class rooms or on the job in training firms. The course curriculum may also include internships. Typical examples of further training schemes are courses on IT based accounting or on customer orientation and sales approach. Similar to the much longer retraining schemes, that lead to a complete new degree within the German apprenticeship system, further training programs aim at improving the human capital and productivity of the participant. Short-term training, in contrast, primarily aims at improving job search and lasts typically about four weeks.

In order to become eligible for training, job seekers have to register personally at the local employment agency. This involves a counseling interview with a caseworker. In principle, they have in addition to fulfill a minimum work requirement and be entitled to unemployment benefits. However, there are exceptions to this rule. The most important criterion is that the training scheme has to be considered necessary by the caseworker for the unemployed to find a new job. Participation in training can occur at any time during an unemployment spell.

Before 2003, training measures were assigned by the caseworker. This was often done in agreement with the job seeker, considering his or her willingness to receive training and to work in a specific field. The final decision was subject to the discretion of the caseworker. Assignment into programs was to a large extent driven by the supply 
of courses that were booked in advance for a year by the employment agencies from training providers. Assignments to training often occurred at very short notice in order to fill course capacities and to keep up job search incentives (Schneider et al., 2006).

In 2003, the assignment procedure changed to a system where the job seeker receives a training voucher from the caseworker valid between one and three months. The voucher specifies the maximal length, the content and the objective of the eligible training program. The job seeker then chooses by himself a suitable course from a pool of certified training providers. The 2003 reform meant to make the allocation process more targeted and selective. However, potential participants were uncertain about the actual starting date because it turned out that training providers tended to collect vouchers until a critical number of participants was reached or they shortly canceled scheduled courses if there were too few participants (Kühnlein and Klein, 2003, Schneider et al., 2006). Moreover, during the first quarter of 2003, the old and new assignment system coexisted. $93 \%$ of the programs in our analysis sample start before the reform. An additional $2 \%$ starts in the first quarter of 2003 . About $5 \%$ of the programs fall in the time period when vouchers were used.

During training most participants receive a subsistence allowance of the same amount as the unemployment compensation they would receive otherwise. Participants not eligible for subsistence allowance may receive similar payments from the European Social Fund. In addition, travel and child-care costs may be covered by the employment agency.

Once a particular program or a training voucher has been assigned, participation is mandatory. Non-compliance is in general sanctioned with a temporary suspension of unemployment compensation. The planned duration of the further training programs considered in this paper is eight months on average. However, not all participants who start a program complete it. In fact, according to Waller (2009), one out of five participants who have started a program and attended it for at least one week drop out before having reached $80 \%$ of the planned duration. About half of the dropouts start employment soon after quitting a program. In many cases this behavior is encouraged by the employment agency because in general employment has priority over participation in active labor market programs. Exceptions from this rule are possible if completing the program is deemed necessary for a stable 
placement. Those dropping out for other reasons are often not sanctioned. As opposed to dropouts, it also happens in some cases that participation in training is prolonged. Due to dropout and possible prolongment of participation the actual duration of training is endogenously determined.

\subsection{Constructing a Panel Data Set}

For the empirical analysis, we construct a panel data set from a rich administrative database, the Integrated Employment Biographies Sample (IEBS). The IEBS is a $2.2 \%$ random sample from a merged data file containing individual data records collected in four different administrative processes: the IAB Employment History (Beschäftigten-Historik), the IAB Benefit Recipient History (LeistungsempfängerHistorik), the Data on Job Search Originating from the Applicants Pool Database (Bewerberangebot), and the Participants-in-Measures Data (Maßnahme-TeilnehmerGesamtdatenbank). The data contain detailed daily information on employment subject to social security contributions, receipt of transfer payments during unemployment, job search, and participation in different active labor market programs. ${ }^{11}$

We consider an inflow sample into unemployment consisting of individuals who became unemployed between the first of July 1999 and the end of December 2000, after having been continuously employed for at least 125 days. Entering unemployment is defined as the transition from non-subsidized employment to non-employment plus subsequently (not necessarily immediately) some contact with the employment agency, either through benefit receipt, program participation, or a job search spell. In order to exclude individuals eligible for specific labor market programs targeted to youths and individuals eligible for early retirement schemes, we only consider persons aged between 25 and 53 years at the beginning of their unemployment spell.

We aggregate the spell information in the original data into calendar quarters. We follow a person in the sample from the quarter of his or her first inflow into unemployment over the next 16 quarters or until the end of 2004, whichever occurs first. For $76 \%$ of the individuals in the sample we observe the full sequence of 17 quarters. The sequences of the remaining individuals are shorter either because we observe less than 17 quarters from their inflow until the end of 2004, or because we

\footnotetext{
${ }^{11}$ For further information on the data see Appendix A.
} 
censor the time path of individuals when they enter a long-term active labor market program other than training. We ignore participation in short-term training and do not censor employment sequences in this case.

We distinguish the two outcome states non-subsidized employment (henceforth denoted as employment) and non-employment as alternative states. We aggregate the employment information measured at a daily level into quarters as follows. First, for short gaps of a length up to 45 days between sequences of longer employment or non-employment spells we extend the longer spells through the gap. Second, we map the start of non-employment and employment spells to the quarterly employment dummy in the following way. If a transition to non-employment occurs during a calendar quarter, the employment dummy is set to zero during this quarter. It continues to equal zero in the following quarter if the elapsed duration of non-employment at the end of the quarter exceeds 90 days. From the third quarter of non-employment onwards, the employment dummy is set to zero if the share of days in non-employment exceeds one half. Third, we adjust our procedure in order to take account of short employment spells that otherwise would be dropped.

Participation in further training is coded as follows. We construct a dummy variable that equals one in the quarter in which the job seeker starts a training program and attends it for at least 27 days. In order to model the duration of the training program we apply the same rules as for the employment dummy above to the qualification dummy. Because not only the start of a program but also the program status in each following quarter is used for the estimation, it is important to use reliable information on the realized program duration. We correct the reported end dates of training programs using the correction procedures proposed in Waller (2008). Participation can already occur in the first quarter we observe for an individual.

The definition of the quarterly employment and training dummy variables mimics the timing of events. When a person starts a training program in one quarter, he is also coded to be non-employed in that quarter. While being in the program, a participant remains non-employed. When a program participant exits to employment in a given quarter, even though he has been in the program at the beginning of this quarter, the training dummy changes to zero in that quarter. Consequently, our empirical analysis imposes a lag in the effect of training, such that training in one quarter is only allowed to have a causal effect on employment in future quarters. 
The panel data set for the analysis is completed by adding personal, occupational and regional information. Information on the regional labor market and the current season is updated at the beginning of each quarter. The estimations are carried out separately for males and females and West and East Germany.

\subsection{Descriptive Analysis}

Table 1 gives an overview of the four samples and their basic characteristics. On average we observe 13 to 15 quarters per person, with the number of non-employment quarters ranging from eight to ten. This corresponds to 1.5 to 1.9 unemployment spells and about one employment spell on average per person. One in ten to one in five persons participate in training throughout the observation period with participation rates being higher in East Germany and among females.

— Insert table 1 about here. -

Planned and realized enrolment lengths in training vary widely. Figure 2 provides histogram plots of planned and realized program durations in the four samples. The height of the bars records the fraction of cases with a program duration corresponding to the value given on the horizontal axis. Realized and in particular planned durations display spikes at certain round dates like six months or one year. The share of realized durations lying below half a year is higher than that of planned durations. This indicates that some trainees drop out before the scheduled program end.

— Insert figure 2 about here. -

Figure 3 illustrates the evolution of the employment and training rates from the quarter of inflow into unemployment onwards. In the calendar quarter of the inflow, all individuals are defined as non-employed. The employment rates subsequently recover, but those of females remain at a slightly lower level than those of males. While participation rates barely reach five percent in West Germany, they peak at about eight to nine percent in East Germany.

- Insert figure 3 about here. - 
Figure 4 gives a first impression of the likely order of magnitude of the treatment effects. It shows the actual employment rate and estimates of the counterfactual employment rate associated with starting a training program in a given quarter versus no training start until that quarter for the treated individuals, where treated and matched controls are only aligned in time. Treatment status is a time-varying variable. This means that training participants who enrol later are counted as controls for those who enrol in an earlier quarter. The matching is performed with respect to the calendar quarter of the first inflow and the elapsed unemployment duration in the current unemployment spell. No adjustments are made for other potential sources of selection bias. West German females show the largest employment differences five to ten quarters after program start, which amount to more than 15 ppoints. The initial lock-in periods characterized by negative employment effects are substantially longer in East Germany than in West Germany.

— Insert figure 4 about here. -

\section{Evaluation Framework}

\subsection{A Framework for Dynamic Treatment Effects}

We have constructed a quarterly panel data set recording transitions into employment and training together with a vector of covariates. Training programs are only open to unemployed individuals. They can start a program at different points in time during their unemployment spell and they can continue training for different periods of time. At the start of the program every participant is assigned a planned program duration. The actual enrollment length is not exogenously given, but also depends on the success of job search. Participants may drop out of a program or prolong training participation. Reentry into training is not possible once a participant has exited a program within a period of three years. Therefore, we model for each individual the sequential process leading to the first participation in training during the observation period which covers up to at most 17 quarters. We model the employment and training transitions as a two equation system with possibly dependent unobservables.

Our approach is similar to the dynamic treatment effect model proposed by Heckman 
and Navarro (2007, henceforth HN). They consider a sequential discrete choice model for the timing of treatment - their leading example is the decision to stop schooling - and the impact of alternative treatment times on continuous or discrete outcomes. Our approach is also similar to the timing-of-events model by Abbring and van den Berg (2003, henceforth AvdB). They consider a bivariate event-history model for the transitions into treatment and into an outcome state, but their framework is in continuous time. Our approach has in common with the other two frameworks that we consider the variation in the moment of treatment over time and specify a joint model for the evolution of treatment and outcome processes over time. Furthermore, our approach as well as HN and AvdB allow for dependent unobservables in the treatment and outcome equations. This means that we allow for selection into treatment based on unobservables. This contrasts with sequential matching methods that rely on a conditional independence assumption, i.e. that treatment status and potential outcomes be independent conditional on observed covariates and lagged endogenous variables. ${ }^{12}$

Our goal is to estimate the causal effect of training on the probability to be employed in a given quarter. We adopt the potential outcome approach to causality (Roy, 1951, Rubin, 1974). We have data on $\left(E_{i t}, Q_{i t}, \boldsymbol{x}_{i t}\right)$, where $i$ indexes individuals and $t=0, \ldots, T$ time periods $(T \leq 16), E_{i t}, Q_{i t}$ are binary indicators for employment and training status, respectively, and $\boldsymbol{x}_{i t}$ denotes a vector of time-constant as well as time-varying covariates. Denote the non-treatment outcome by $E_{t}(0)$, assuming no treatment until period $t$. Let $s$ index the starting period of training and $u$ the first period after the end of training, where $s<u$. $E_{i t}(s, u)$ denotes the potential outcome in $t$ associated with training taking place during the time interval $[s, u)$. The variables $s$ and $u$ are related to $Q_{i t}$ in the following way: $Q_{i t}=1$ for $s \leq t<u$ and $Q_{i t}=0$ for $t<s$ and $t \geq u$. Thus, $s$ and $u$ can be interpreted as the realizations of two duration variables, i.e. the duration in open unemployment until program start $(s)$ and the duration of training $(u-s)$, both measured in discrete time. For ease of notation, we will omit the $i$-subscript in the following.

Corresponding to the binary variables $Q_{t}, E_{t}(0)$, and $E_{t}(s, u)$ are the latent continuous random variables $Q_{t}^{*}, E_{t}^{*}(0)$, and $E_{t}^{*}(s, u)$, respectively. We define $Q_{t}=\mathbb{1}\left(Q_{t}^{*}>\right.$ $0)$ and - with slight abuse of notation $-E_{t}(j)=\mathbb{1}\left(E_{t}^{*}(j)>0\right), j \in\{0,(s, u)\}$,

\footnotetext{
${ }^{12}$ See Abbring and Heckman, 2007, for a survey of different evaluation approaches in settings with dynamic treatment assignment.
} 
where $\mathbb{1}($.$) is the indicator function. The latent training and employment variables$ are assumed to be additively separable in an index summarizing the influence of observables, $\psi_{j}(\cdot)$, and an error term, $\nu_{j}, j=0,(s, u), Q:^{13}$

$$
\begin{aligned}
& Q_{t}^{*}=\psi_{Q}\left(t, \boldsymbol{x}_{t}, Q^{t-1}, E^{t-1}\right)+\nu_{Q, t} \\
& E_{t}^{*}(0)=\psi_{0}\left(t, \boldsymbol{x}_{t}, E^{t-1}\right)+\nu_{0, t} \\
& E_{t}^{*}(s, u)=\psi_{s, u}\left(t, \boldsymbol{x}_{t}, E^{t-1}, Q^{t-1}, P\right)+\nu_{(s, u), t}
\end{aligned}
$$

where $P$ corresponds to the planned program end that is assigned when the program starts. The observed past treatment sequence is defined by $Q^{t-1}=\left(Q_{0}, \ldots, Q_{t-1}\right)$ and the observed past employment sequence by $E^{t-1}=\left(E_{0}, \ldots, E_{t-1}\right)$. For instance, we have $Q^{t}=0$ for $t<s$.

Our analysis estimates ex post treatment effects (i.e. treatment effects that occur in or after period $s$ ) and we rule out ex ante treatment effects. This is motivated by the fact that, in Germany, training enrolment occurs on a short-term basis such that the moment of program start cannot be anticipated by the unemployed. Consequently, $E_{t}(s, u)$ refers to the post-treatment outcome for $t \geq s$. Under the no-anticipation assumption, which rules out ex ante treatment effects before program start, latent pre-treatment outcomes coincide with latent non-treatment outcomes $E_{t}^{*}(s, u)=$ $E_{t}^{*}(0)$ for $t<s$. This implies that actual outcomes coincide, i.e. $E_{t}(s, u)=E_{t}(0)$ for all $t<s$. Since training participation can only occur during unemployment, treatment outcomes are zero during participation, i.e. $E_{t}(s, u)=0$ if $s \leq t<u$.

Similar to no-anticipation of program starts, we also assume no-anticipation of the actual program end $u$ for individuals currently participating in training during period $t$ when $s \leq t<u$. Thus, we assume for the latent employment variables

$$
E_{t}^{*}(s, u)=E_{t}^{*}\left(s, u^{\prime}\right), \text { if } s \leq t<\min \left(u, u^{\prime}\right)
$$

Recall that actual employment is zero during participation. Assumption (2) means that, holding everything else constant $\left(\left[\boldsymbol{x}_{t}, E^{t-1}, Q^{t-1}, P\right]\right.$, i.e. the conditioning set in equation 1), the latent potential outcomes do not differ before the end of the shorter realized training duration. Thus, future decisions about the continuation of training do not affect the latent treatment outcomes at present, even after the start of the program. This allows us to estimate the causal effect of different actual program durations on employment outcomes.

\footnotetext{
${ }^{13} \mathrm{AvdB}$ and HN impose conceptually similar forms of separability between observed and unobserved components.
} 
The evaluation problem consists in recovering the counterfactual outcome $\mathrm{E}\left[E_{t}(0) \mid s, u\right]$, i.e. the employment probability in period $t$ of those who have started training in period $s$ and finished treatment in period $u$ had they instead never started training before $s \leq t$. Our data yield sample analogues of

$$
\mathrm{E}\left[E_{t}, Q^{t}=(0)\right]=\mathrm{E}\left[E_{t} \mid Q^{t}=(0)\right] \times \operatorname{Pr}\left(Q^{t}=(0)\right)
$$

i.e. nontreatment outcomes for those who have not started treatment until $t$. Here the conditioning on observed covariates and lagged employment is kept implicit.

Denote by $S$ and $U$ two random variables for the start and end of training with $S<U$. Our first estimand of interest is the average effect of treatment on those starting treatment in $S$ after $\pi=(t-S)$ periods conditional on $S \leq t$,

$$
\begin{gathered}
A T T_{1}(\pi)=\mathrm{E}_{S, U}\left\{\mathrm{E}\left[E_{S+\pi}(S, U)-E_{S+\pi}(0) \mid S, U\right]\right\} \\
=\sum_{s, u} \mathrm{E}\left[E_{s+\pi}(s, u)-E_{s+\pi}(0) \mid s, u\right] \times \operatorname{Pr}_{\pi}(s, u \mid S+\pi \leq T),
\end{gathered}
$$

where $E_{s+\pi}(\cdot)$ is the potential outcome in period $t=s+\pi$ and the condition $S+\pi \leq$ $T$ guarantees that the time period lies before the end of the observation period $T$. We consider the sample distribution of $s, u$ in any period $t$ after treatment start holding $\pi$ (time since start of program) constant, i.e. $\operatorname{Pr}_{\pi}(s, u \mid S+\pi \leq T)$. As we assume conditional independence between the timing of treatment and potential outcomes conditional on observed covariates and the unobserved heterogeneity components considered in equation (1) expression (4) is equal to zero for $\pi<0$.

The main intuition for establishing identification is as follows. If we can recover the joint distribution of $\left(\nu_{0, t}, \nu_{Q, 1}, \ldots, \nu_{Q, t}\right)$ from sample estimates of equation (3), we know the joint distribution of $\left(\nu_{0, t}, \nu_{Q, 1}, \ldots, \nu_{Q, s}\right), s \leq t$ and of $\left(\nu_{0, t}, \nu_{Q, 1}, \ldots, \nu_{Q, u}\right)$ for $u<t$. Thus, we can construct average counterfactual outcomes $\mathrm{E}\left[E_{t}(0) \mid s, u\right]$, both for $s \leq t<u$ (during treatment) and for $u \leq t$ (after treatment), and the corresponding treatment effects $\mathrm{E}\left[E_{t}(s, u)-E_{t}(0) \mid s, u\right] .{ }^{14}$

HN show that the joint distribution of $\left(\nu_{0, t}, \nu_{Q, 1}, \ldots, \nu_{Q, t}\right)$ is nonparametrically identified provided there exists sufficient exogenous variation across equations and across time, such that the indices of the treatment and outcome equations in each period can be varied independently of each other over their full support and that there

\footnotetext{
${ }^{14}$ Similarly, one could also analyze the period $t$ effect of training during period $[s, u)$ versus $\left[s^{\prime}, u^{\prime}\right)$, $s \leq s^{\prime}, u \leq u^{\prime}$, for those who get training in $[s, u)$, i.e. $\mathrm{E}\left[E_{t}(s, u)-E_{t}\left(s^{\prime}, u^{\prime}\right) \mid s, u\right], s \leq s^{\prime}, u \leq u^{\prime}$.
} 
exist limit sets in which the probability of a given treatment sequence under consideration is equal to one (see Theorem 2 in HN). Such independent variation can be obtained through time-varying instrumental variables or through other crossperiod and cross-equation restrictions that are implied e.g. by structural modeling approaches or functional form assumptions. In practice, it is extremely difficult in dynamic setups as ours to justify exclusion restrictions by economic arguments. This would require time-varying variables which affect training transitions and whose time path is not anticipated and acted on by the individuals eligible for training (see Abbring and van den Berg, 2003, 2005). In our application, we therefore impose some weak parametric structure and exploit identifying restrictions implied by the regulation of training provision in Germany as well as the richness of our data that include a large variety of time-constant as well as time-varying regressors.

The second treatment parameter we consider is the so-called effect of 'treatment now versus waiting' (Sianesi, 2004), which we adjust to our setting of modeling the training duration. This is the effect of starting training in period $s$ of duration $u-s$ versus not starting treatment in period $s$, which entails the possibility that some training participation occurs at a later point in time:

$$
A T T_{2}(\pi)=\sum_{s, u} \mathrm{E}\left[E_{s+\pi}(s, u)-E_{s+\pi}(0(s)) \mid s, u\right] \times \operatorname{Pr}_{\pi}(s, u \mid S+\pi \leq T),
$$

where $0(s)$ denotes nonparticipation until period $s$, which entails the possibility that training starts in period $s+1$ analogous to the distribution observed in the sample. Identification of this effect follows the same line of reasoning as above. In the matching literature following Sianesi (2004), the focus lies on $\mathrm{E}\left[E_{s+\pi}(s, u)-\right.$ $\left.E_{s+\pi}(0(s)) \mid s, u\right]$, i.e. the effect of starting training in $s$ versus not yet for those individuals at risk of being assigned to treatment in period $s .^{15}$ The matching approach does not specify a model for the selection across time. As the population of individuals eligible for treatment in any period $s$ changes over time, impact estimates that are averaged across starting dates are not causal. In contrast, our approach that models the dynamic selection across time allows us to do this. By comparing our estimated treatment effects corresponding to equation (4) to those of equation (5) we are able to asses the order of magnitude by which matching analogous to Sianesi (2004) under- or overestimates the effect of treatment versus no treatment in equation (4) due to the inclusion of future participants in the control group.

\footnotetext{
${ }^{15}$ See Biewen et al. (2007) for an application using this approach with German register data similar to those used here.
} 
Third, we analyze the differential causal effects associated with different planned enrollment lengths in training. We could also estimate the causal effect of varying the realized end of training from $u$ to $\tilde{u}>u$, for those receiving training during $[s, u) .{ }^{16}$ However, we cannot identify the opposite effect of attending for a longer duration for those who enrol for the longer duration without imposing some structure on the dependence of the unobservables across time.

Because of this limitation and because the planned duration is the actual policy parameter, which is manipulated by the caseworker, we estimate the effect of varying the planned end date $P$. Our estimate accounts for the fact that the actual duration of the program is affected by the planned end date (see equation 1) but the realized end of the program cannot be anticipated at the beginning of the program. This is because the error term $\nu_{Q, t+1}$ cannot be predicted for sure by the trainees based on the information available in period $t$.

Our third parameter of interest is:

$$
\begin{gathered}
A T T_{3}(\pi)= \\
\sum_{s, u}\left\{\mathrm{E}\left[E_{s+\pi}(s, u(p))-E_{s+\pi}(s, u(\tilde{p})) \mid s, u\right]\right\} \times \operatorname{Pr}_{\pi}(s, u \mid S+\pi \leq T),
\end{gathered}
$$

where $p$ and $\tilde{p}$ denote two different given planned enrollment lengths and $u(p), u(\tilde{p})$ are the end dates as functions of different planned durations. We still integrate over the sample treatment group, denoted by the actual training period $[s, u)$. Our motivation for studying $A T T_{3}(\pi)$ is as follows. While the realized training duration is endogenous and related to the success of job search, planned training duration is determined at the moment of enrollment. Thus, we can treat it as an exogenous covariate conditional on observed covariates, the employment and training history, and the random effect in the training duration. This way, we provide evidence on the effect of the ex ante assignment of planned durations.

\footnotetext{
${ }^{16}$ This is given by
}

$$
\mathrm{E}\left[E_{s+\pi}(s, u)-E_{s+\pi}(s, \tilde{u}) \mid s, u\right]
$$

Our data yield sample analogues of

$$
\left.\mathrm{E}\left[E_{t}, S=s, U=\tilde{u}\right]=\mathrm{E}\left[E_{t} \mid S=s, U=\tilde{u}\right)\right] \times \operatorname{Pr}(U=\tilde{u} \mid S=s) \times \operatorname{Pr}(S=s),
$$

with $s \leq t$, which allows us to identify the joint distribution of $\left(\nu_{(s, \tilde{u}), t}, \nu_{Q, s}, \ldots, \nu_{Q, t} \mid \nu_{Q}^{s-1}\right), s \leq t \leq$ $\tilde{u}$ in a way analogous to above. This would allow us to construct average counterfactual outcomes $\mathrm{E}\left[E_{t}(s, \tilde{u}) \mid s, u\right], u<\tilde{u}$. Thus, we can identify the effect of attending for a shorter duration compared to a longer duration for those who actually enrol for the shorter duration. 


\subsection{Implementation}

We impose some weak parametric structure when implementing our approach. Specifically, we specify the latent indices summarizing the influence of observed covariates as linear in parameters:

$$
\begin{array}{ll}
\psi_{Q}\left(t, \boldsymbol{x}_{t}, Q^{t-1}\right) & =\boldsymbol{\mu}_{Q}\left(t, \boldsymbol{x}_{t}, Q^{t-1}\right) \boldsymbol{\eta}_{Q} \\
\psi_{0}\left(t, \boldsymbol{x}_{t}, E^{t-1}\right) & =\boldsymbol{\mu}_{0}\left(t, \boldsymbol{x}_{t}, E^{t-1}\right) \boldsymbol{\eta}_{0} \\
\psi_{(s, u)}\left(t, \boldsymbol{x}_{t}, E^{t-1}, Q^{t-1}, P\right) & =\boldsymbol{\mu}_{(s, u)}\left(t, \boldsymbol{x}_{t}, E^{t-1}, Q^{t-1}, P\right) \boldsymbol{\eta}_{(s, u)}
\end{array}
$$

where $\boldsymbol{\mu}(\cdot)$ denotes a vector-valued function and $\boldsymbol{\eta}$ a conformable coefficient vector. This parametric structure is far less restrictive than it may seem at first glance. In fact, we have access to a data set that comprises large sample sizes and a rich set of covariates. First, we stratify the data by gender and region (West and East Germany) and run separate estimations for each of the four strata. Second, many variables are indicators referring to different categories of finely coded discrete variables. As far as the data permit, we specify fully saturated models. Third, for the continuous regressors we use polynomials and various interactions with the discrete variables in our specifications. In particular, we model state dependence and duration dependence in a very flexible way, allowing for interactions with observed covariates. ${ }^{17}$ Our data also include time-varying variables. They provide the necessary exclusion restrictions across time. If the combined design matrix from the employment and the participation equation has full rank the joint distribution of $\left(\nu_{(0), t}, \nu_{Q, 1}, \ldots, \nu_{Q, t}\right)$ and $\left(\nu_{(s, u), t}, \nu_{Q, 1}, \ldots, \nu_{Q, u}\right)$ is identified nonparametrically in our application. The rank condition can easily be checked in our application by noting that some regressors are significant in one equation but not in the other and therefore omitted from that equation.

Furthermore, we assume that the error terms each comprise a permanent and a transitory component:

$$
\begin{aligned}
& \nu_{Q, t}=\alpha_{Q}+\varepsilon_{Q, t} \\
& \nu_{j, t}=\alpha_{E}+\varepsilon_{j, t}, \quad j=0,(s, u)
\end{aligned}
$$

where the $\left(\varepsilon_{0, t}, \varepsilon_{(s, u), t}, \varepsilon_{Q, t}\right)$ are mutually independent idiosyncratic error terms that are independent of the individual specific effects $\left(\alpha_{Q}, \alpha_{E}\right)$. The latter are allowed to be correlated with each other. Thus, a nonzero correlation between the individual

\footnotetext{
${ }^{17}$ In the continuous-time timing-of-events approach, researchers commonly rely on more restrictive specifications of duration dependence. In particular, separability between the model components referring to duration dependence and observed covariates is often imposed.
} 
specific effects $\left(\alpha_{Q}, \alpha_{E}\right)$ gives rise to a spurious dependence between training and employment status even if the treatment effect is zero. Our specification of the unobservables is similar to other dynamic treatment effect approaches, in particular those by AvdB and HN, that also assume separability between the effects of observed and unobserved model components and that a low dimensional set of time constant unobserved heterogeneity terms generates the dependence over time and across equations. Unlike HN, we do not model $\alpha_{E}$ to be a function of treatment status, but we use our rich data to model effect heterogeneity across observables in a flexible way. In order to estimate the model we choose independent standard normal distributions for the idiosyncratic errors and a bivariate normal distribution for the individual specific effects.

This structure of the unobservables together with the restrictions implied by the institutional setup provide additional identifying power. In fact, our identification strategy can be viewed as a discrete time version of the timing-of-events approach by $\mathrm{AvdB}$. The basic idea translated to our setting is as follows. In our institutional setup the unemployed are assigned to training programs on a short-term basis, such that the participants do not know the exact starting date of their program in advance. Hence, treatment effects can only occur once the program has started and we can use pre-treatment observations to identify the correlation between the random effects in the training and the employment equation. Then, the differential association between employment and training status that arises after program start is evidence for a nonzero treatment effect.

To sum up, we propose a semiparametric identification strategy that relies on mild functional form assumptions, restrictions implied by the institutional setup, and rich data. We specify a similar structure for the unobservables as suggested in AvdB and HN. We allow for a rich set of observed covariates and a great flexibility in the way they enter the employment and training equations. In this respect, our approach is similar to matching analyses that rely on a rich and flexible specification of the observed heterogeneity. In contrast to matching methods, we allow in addition for selection into and out of training based on unobservables. In addition, our estimates allow for heterogeneity of treatment effects across observed covariates. 


\subsection{Specification}

We now describe how we specify the employment and training equation. ${ }^{18}$ Consider first the employment equation. In order to model the employment dynamics we introduce employment lags up to the order of 15 (i.e. $E_{i(t-1)}, E_{i(t-2)}, \ldots, E_{i(t-15)}$, where $i$ indexes individuals and $t$ quarters) as explanatory variables for current employment status. A lagged variable only kicks in if the inflow into unemployment has not been too recent for the corresponding lag to be available, i.e. the $j$ th lag kicks in if $t-j \geq 1$. This way we account for the entire employment history since the inflow into unemployment, thus accounting for both state dependence and duration dependence in the most flexible way, based on our discrete time data. Furthermore, we include calendar time and a vector of observed characteristics, $\boldsymbol{x}_{i t, E}$, in the employment equation. In particular, we use information on schooling and occupational qualification, age, occupation, and earnings in the previous jobs, number of days employed in the last three years before the inflow into unemployment, health, children, labor market characteristics of the residential municipality, season and year. In addition, we control in a flexible way for the elapsed number of quarters an individual is in the panel, $t$, and the elapsed duration in the current employment or non-employment spell, denoted by $\tau_{i t, E}$. Finally, we allow for a large number of interaction effects between lagged employment status, elapsed duration, and covariates.

The employment equation includes lagged training status whose impact is modeled in a flexible way. The dummy variable $Q_{i(t-1)}$ indicates whether the individual attended a training program in the previous quarter. If this dummy equals one, lagged training is depicted by a dummy if participation so far has lasted two quarters $\left[Q_{(t-1)}=1\right] \times\left[Q_{(t-2)}=1\right] \times\left[Q_{(t-3)}=0\right]$, three quarters $\left[Q_{(t-1)}=1\right] \times\left[Q_{(t-3)}=\right.$ $1] \times\left[Q_{(t-4)}=0\right]$, four quarters $\left[Q_{(t-1)}=1\right] \times\left[Q_{(t-4)}=1\right] \times\left[Q_{(t-5)}=0\right]$ and so forth. We distinguish explicitly the effects on the exit from nonemployment in the next quarter while being in training from the effect on future employment in subsequent quarters after training has ended. To do so, we add a dummy $D_{i t}$ indicating whether an individual has ever participated in training since the inflow quarter. For trainees who have already exited the program, i.e. individuals having received training before quarter $t-1$ for whom the dummy on participation in

\footnotetext{
${ }^{18}$ The details of the specification can be found in the table 5 results in Appendix C.
} 
training in the last quarter $Q_{i(t-1)}$ is zero, $D_{i t}$ is equal to one. We account for the training history by interacting $D_{i t}$ with $\tau_{i t, Q}$, which in this case indicates the completed duration, as well as a polynomial of the elapsed quarters since program start, $\pi_{i t}=t-s_{i}$ for the individual. An interaction effect of $\tau_{i t, Q}$ and $\pi_{i t}$ is also added. To allow for state dependence of the training effects in the outcome equation, the variables reflecting training history are interacted with other explanatory variables in the employment equation and the first lag of employment status $E_{i(t-1)}$.

Consider next the training equation modeling the transition into and out of training. It is estimated simultaneously with the employment equation if the individual is not employed in the respective quarter and has not yet left a training program. Since participation can only occur during non-employment the two equation system reduces to a single equation for observations for which the employment status, $E_{i t}$, is equal to one. Then, the treatment equation is switched off. The vector of observed regressors, $\boldsymbol{x}_{i t, Q}$, includes variables driving the decision to enter and to stay in a program. The covariate vector comprises a dummy indicating whether the individual was enrolled in training in the previous quarter, $Q_{i(t-1)}$, a variable for the elapsed quarters in the program $\tau_{i t, Q}$, a polynomial of the time until the planned end (in case the planned duration is not yet exhausted) and a dummy if the planned end is missing in the data. These variables are equal to zero if the individual has not yet started training $\left(Q_{i(t-1)}=0\right)$. Furthermore, the vector of independent variables includes variables summarizing the current unemployment experience, dummy variables indicating whether the current quarter is the inflow quarter, as well as whether a repeated transition from employment to non-employment has occurred, and a polynomial of the elapsed unemployment duration in days. Finally, information on age, schooling, vocational training, last job, number of days in employment during the last three years before the inflow, health, children and entitlement to unemployment compensation, season, and year are incorporated.

\subsection{MCMC Estimation}

We estimate the bivariate random effects probit model for employment and training transitions introduced in the previous section using Bayesian Markov Chain Monte 
Carlo (MCMC) techniques. ${ }^{19}$ The draws of the parameters along the MCMC iterations allow us to estimate the posterior distribution of the parameters and of functions thereof. From a classical perspective, the mean of the posterior distribution converges to the point estimator from a maximum likelihood estimation and the variance of the posterior distribution converges to the asymptotic variance of the point estimator in a maximum likelihood estimation. Thus, the standard deviation of the draws may be interpreted as standard errors from the classical perspective (see Train, 2003, for an overview over important properties of MCMC estimators). To obtain a sample from the posterior distribution, we use the Gibbs sampler. To simplify the sampling from a complex joint distribution, the Gibbs sampler forms blocks of model parameters and samples recursively from the distribution of one block conditional on the current values of the remaining parameters. The resulting sequence of simulated parameters is a Markov Chain whose invariant distribution is the desired posterior distribution. After convergence, the draws are samples from this posterior distribution.

The key idea for the estimation of probit models is to augment the data by simulating the continuous latent employment and training variables as one step of the Gibbs sampler and to use standard linear regression techniques to obtain the corresponding draws for the $\boldsymbol{\eta}_{j}$-coefficients, $j=E, Q$ (Albert and Chib, 1993). Furthermore, one step of the Gibbs sampler involves sampling the random effects $\alpha_{E, i}, \alpha_{Q, i}$ conditional on the data and the remaining model parameters (Zeger and Karim, 1991). The posterior distribution of the individual specific random effects allows to estimate the expected value of the random effects for a given individual given the data and the prior distribution of parameters. These predictions can be used to assess selectivity effects between training and employment.

We provide details of the algorithm in Appendix B. Conjugate but very diffuse priors are used. The results reported below are obtained from running 50,000 iterations of the algorithm. We monitor convergence by comparing the means at different stages of the chains. We discarded the first 5,000 iterations (the burn-in phase). Thus, our results are based on 45,000 draws. We implemented the Gibbs sampler in Stata.

\footnotetext{
${ }^{19}$ See Chib (2001) for a survey of MCMC techniques. See Chib and Hamilton (2002) and Chib and Jacobi (2007) for applications of MCMC methods for the estimation of treatment effects. These papers analyze binary treatments and allow for heterogeneous treatment effects in terms of unobservables.
} 


\subsection{Estimation of Treatment Effects}

The raw coefficient estimates are difficult to interpret because of the complex dynamic structure of the model involving many interaction effects. Therefore, we directly analyze the posterior distribution of several treatment effects of interest. While in section 3.1 we stated these effects formally, here we give a short nontechnical reminder of the different average treatment effects on the treated (ATT):

Classical $\boldsymbol{A T T}\left(A T T_{1}\right)$. This is the ATT of training versus non-participation during the observation period.

Training versus Waiting $\left(A T T_{2}\right)$. At any given quarter, those starting training during this quarter are counted as treated whereas those not yet enrolling are assigned to the control group. The latter may potentially participate in a later quarter. This effect mimics the treatment parameter suggested by Sianesi (2004) and estimated in several subsequent papers for European training programs using propensity score matching (see for example Biewen et al., 2007).

Effect of a Given Planned Program Duration (ATT 3 ). Among the treated individuals, we estimate the effects of different planned program durations, allowing for the realized program length to be endogenous. In particular, we compare the effect of attending a program with a planned length of one, three, and four quarters, respectively, to attending a program with a planned duration of two quarters.

To estimate these treatment effects, we simulate draws from the posterior distribution of these treatment effects based on the sequence of MCMC iterations. To account for selection based on unobservables, we use the draws of the random effects $\alpha_{E, i}$ and $\alpha_{Q, i}$ from the MCMC estimation of the model. The details of the simulation procedure are given below.

First, we describe the simulation of the Classical ATT. For every 30th draw of the MCMC iterations (after the burn-in phase), we go through the following steps:

Step 1. For each participant, predict the treatment outcome $E_{i t}^{1}$ starting with the first period after program participation $(t-u=0$, where $u$ denotes the first 
quarter after the end of program participation).$^{20}$ In particular, go from $t-u=$ 0 to $t-u=9$ and predict the employment status for each period based on the corresponding draw from the vector of coefficients $\eta_{E}$, the vector of explanatory variables, denoted $z_{E, i t}$, the corresponding draw of the $\alpha_{E, i}$ and a draw of the idiosyncratic error term $\varepsilon_{E, i t}$. The dynamic elements of $z_{E, i t}$, such as lags of employment status, are updated when moving from one quarter to the next. $\varepsilon_{E, i t}$ is drawn from a standard normal distribution. ${ }^{21}$

Step 2. For each participant, simulate the counterfactual employment outcome (i.e. the outcome if the participant had not participated in a program) $E_{i t}^{0}$ for each period beginning with the quarter of program start $(t-s=0$, where $s$ denotes the first quarter of program participation). Again go through the dynamic process and predict the employment status for each period based on the same $\eta_{E}, \alpha_{E, i}$ and $\varepsilon_{E, i t}$ as before. Adapt the $z_{E, i t}$ to a situation with no participation and update them while going through the process.

Step 3. To get a draw of the ATT aligned to the end of the program, average the difference of the two predictions over all treated individuals $\left(N_{1}\right)$, i.e. $\frac{1}{N_{1}} \sum_{i=1}^{N_{1}}\left(E_{i, t-u}^{1}-E_{i, t-u}^{0}\right)$, for each period $t \geq u$. This gives a draw from the posterior distribution of the ATT for each quarter.

Step 4. For a draw of the ATT aligned to the start of the program, average the difference of the two predictions over all treated individuals, i.e. $\frac{1}{N_{1}} \sum_{i=1}^{N_{1}}\left(E_{i, t-s}^{1}-\right.$ $\left.E_{i, t-s}^{0}\right)$, for each period $t \geq s$.

The resulting 1,500 draws provide an estimate of the posterior distribution of the Classical ATT. We estimate the ATT by the mean of the posterior distribution and we use the standard deviation as our estimate of estimation uncertainty.

Second, the estimation of the posterior distribution of the effect of Training versus Waiting proceeds in an analogous way. Step 1 remains the same. The counterfactual employment outcome $E_{i t}^{w}$ relates to a situation in which the participant does not start a program in the observed start quarter $(s)$, so the employment status $E_{i t}^{w}$ is simulated and $Q_{i t}^{w}$ is set to zero. The individual may start a program later.

\footnotetext{
${ }^{20}$ During program participation, the employment dummy is equal to zero.

${ }^{21}$ We also simulate the observed treatment outcome for the treated because this way the posterior distribution of the treatment effects takes account of the randomness of the treatment outcomes.
} 
Thus, from $t>s$ onwards, the counterfactual employment status $E_{i t}^{w}$ and the counterfactual participation status $Q_{i t}^{w}$ are simulated in turn, adapting the elements of $\boldsymbol{z}_{E, i t}$ and $\boldsymbol{z}_{Q, i t}$ that include lagged employment or participation status while going through the dynamic processes. Note that we do not allow $Q_{i t}^{w}$ to equal one if $E_{i t}^{w}=1$ or if somebody has already left a program. The simulation of $E_{i t}^{w}$ uses the respective draw of $\boldsymbol{\eta}_{E}$ and $\alpha_{E, i}$. The simulation of $Q_{i t}^{w}$ relies on the draw of $\boldsymbol{\eta}_{Q}$ and $\alpha_{Q, i}$. The same $\varepsilon_{E, i t}$ as in step 1 are used and the $\varepsilon_{Q, i t}$ are drawn from a standard normal distribution. In order to calculate a draw of the effect of Training versus Waiting aligned to the start of the program, average the difference of the two predictions for each period over all participants: $\frac{1}{N_{1}} \sum_{i=1}^{N_{1}}\left(E_{i, t-s}^{1}-E_{i, t-s}^{w}\right)$. Likewise, calculate $\frac{1}{N_{1}} \sum_{i=1}^{N_{1}}\left(E_{i, t-u}^{1}-E_{i, t-u}^{w}\right)$ to get a draw aligned to the end of the program.

Finally, consider the Effect of a Given Planned Program Duration. For every 30th draw, we simulate the employment status for different planned program durations. First, we simulate the employment status and participation status for a situation in which all participants are assigned to a program with a planned length of two quarters. $^{22}$ In the quarter in which a given participant starts the program $(t=s)$, $Q_{i t}^{p 2}$ is set to one and $E_{i t}^{p 2}$ is set to zero, as in the original data. In the next quarter $(t-s=1), E_{i t}^{p 2}$ also remains the same as in the original data. The participation status $Q_{i t}^{p 2}$ in $s$ is then simulated and in the following quarters $t-s>1, E_{i t}^{p 2}$ and $Q_{i t}^{p 2}$ are simulated in turn for each period. The elements of $\boldsymbol{z}_{E, i t}$ and $\boldsymbol{z}_{Q, i t}$ that include lags of employment or participation status are adapted while going through the dynamic processes. Again, the values of $\boldsymbol{\eta}_{E}, \boldsymbol{\eta}_{Q}, \alpha_{E, i}, \alpha_{Q, i}$ of the corresponding draw are used. $\varepsilon_{E, i t}$ and $\varepsilon_{Q, i t}$ are drawn from a standard normal distribution, respectively. Similarly, the employment status and the participation status are simulated for each period for the alternative scenario in which the planned program duration is set to one quarter $\left(E_{i t}^{p 1}\right.$ and $\left.Q_{i t}^{p 1}\right)$, three quarters $\left(E_{i t}^{p 3}\right.$ and $\left.Q_{i t}^{p 3}\right)$, and four quarters $\left(E_{i t}^{p 4}\right.$ and $\left.Q_{i t}^{p 4}\right)$, respectively. The same $\varepsilon_{E, i t}$ and $\varepsilon_{Q, i t}$ as before are used. As the median planned duration of the programs in the data is about two quarters, we take $E_{i t}^{p 2}$ as a benchmark and calculate the effect of a planned duration

\footnotetext{
${ }^{22}$ In terms of the model specification, this means that the explanatory variables in the participation equation involving the planned end date (i.e. days/91 until planned end if enough duration left and days/91 until planned end if enough duration left squared) are adapted to this scenario. As these variables are measured in days, the decision whether there is still enough planned duration left and the values these variables take depend on the day within a quarter at which the program starts. Note that it is possible in the simulation as well as in the original data that realized program participation continues beyond the planned end date. The variable planned end missing is set to zero.
} 
of one quarter as opposed to two quarters $\left(\frac{1}{N_{1}} \sum_{i=1}^{N_{1}}\left(E_{i, t-s}^{p 1}-E_{i, t-s}^{p 2}\right)\right)$, of three quarters versus two quarters $\left(\frac{1}{N_{1}} \sum_{i=1}^{N_{1}}\left(E_{i, t-s}^{p 3}-E_{i, t-s}^{p 2}\right)\right)$, and four quarters versus two quarters $\left(\frac{1}{N_{1}} \sum_{i=1}^{N_{1}}\left(E_{i, t-s}^{p 4}-E_{i, t-s}^{p 2}\right)\right)$ for each period $\left.0 \leq t-s \leq 9\right\}$. Again, we estimate the posterior distribution based on 1,500 draws from the simulations for the MCMC iterations.

\section{Estimation Results}

We estimate the impact of incidence and duration of training on the transition probabilities between employment and non-employment using the MCMC estimation approach described in the previous section. Our empirical model accounts for selection into training based on observables and unobservables. Estimation is carried out separately for West German males, West German females, East German males, and East German females. The detailed estimation results are given in table 5 in Appendix C. The first column for each sample refers to the mean of the coefficients and the second to their standard deviation over MCMC iterations after the burn-in phase. We interpret them in an analogous way as the point estimates and standard errors of the coefficients obtained by a frequentist approach. Next, we briefly discuss the overall fit of the model and the individual level variances of the error terms. Because of the complexity of the model (it comprises about 160 parameters), we refrain from further discussing single parameters. Rather, we assess the estimated model in general and discuss the results for different treatment effects of interest.

\subsection{Model Fit and Selection on Unobservables}

Evidence on the fit of the model is provided in table 2 for the treated individuals from the start of the program onwards along with information on the number of observations available in each quarter. Actual and predicted employment rates of the trainees match closely in all four samples. Thus, our rich model specification does a good job in replicating the employment dynamics found in the data. This suggests that our model is not grossly misspecified.

— Insert table 2 about here. - 
The last panel of table 5 in Appendix $\mathrm{C}$ displays results on the variances and covariances of the error terms of the employment and the training equation. The share of the variance that is due to the random effects varies between $36 \%$ and $51 \%$ for the employment equation and between $22 \%$ and $31 \%$ for the training equation. Except for the sample of West German females, the correlation between the two random effects tends to be significantly negative. The correlation coefficient is -.22 and significant at the five percent level for females in East Germany. It is -.11 to -.12 for West and East German males and significant at the ten percent level. This suggests that - in terms of their unobservables - those individuals who have a higher unobserved propensity to enter a program and to stay in a program tend to have a lower unobserved propensity to be employed.

\subsection{Classical Treatment Effect on Employment and on Tran- sition Rates}

Figure 5 shows the average effect of training versus no training for participants on the probability to be employed in a given quarter. ${ }^{23}$ More precisely, we compare the average of the actual employment outcomes of trainees with the expected counterfactual outcome obtained by setting the lags of training status in the employment equation to zero. We obtain actual as well as counterfactual outcomes through simulation using the estimated distribution of the model paramters from the sequence of MCMC iterations. In figure 5, the average difference in the quarterly employment rates is depicted on the vertical axis, while quarters since program start are measured on the horizontal axis. The dashed lines around the estimated treatment effects are 95 percent confidence bands. The treatment effect for a particular quarter is statistically significant if the confidence band does not contain zero. As can be seen, a participation in training reduces the employment probability during the first three to five quarters after program start. During the first two quarters $(\pi=t-s \leq 1)$ the employment probabilities of participants decline between seven (East German females) and 15 (East German males) ppoints compared to the situation of no participation. This lock-in effect lasts one quarter longer in the East German samples compared to the West German ones. After the first year counted from the quarter of program start, the difference in employment rates turns positive and continues to increase until the end of the observation window. Ten quarters after program

\footnotetext{
${ }^{23}$ The corresponding numbers are given in table 6 in Appendix C.
} 
start $(\pi=t-s=9)$, West German females have a 21 ppoints higher employment probability than in the absence of training. The effects are of similar magnitude for East German females (17 ppoints) and somewhat smaller for the male samples (12 ppoints).

— Insert figure 5 about here. -

Based on the model simulations used to calculate the classical ATT, we also calculate transition rates from non-employment to employment and from employment to non-employment. Table 3 depicts the difference in transition rates from nonemployment to employment based on the simulated treatment outcomes as opposed to the simulated non-treatment outcomes. Table 4 depicts the difference in transition rates from employment to non-employment. When calculating the transition rates, the denominator is the number of individuals in non-employment (or employment, respectively) in the previous quarter. This number may differ between the situation where the individuals are treated and the counterfactual situation, thus the differences in transition rates cannot be interpreted as conventional treatment effects because the outcome in the previous quarter is affected itself by the treatment.

The results of table 3 suggest higher transition rates from non-employment to employment due to training after a lock-in period of two to three quarters. The difference in transition rates between the treatment and the non-treatment scenario reaches its maximum four quarters after treatment start, that is soon after the planned end of a typical program. Table 4 indicates much lower transition rates from employment back to non-employment, suggesting that training increases subsequent employment stability.

— Insert table 3 about here. -

- Insert table 4 about here. -

\subsection{Training versus Waiting}

In the recent evaluation literature, researchers often estimate the effect of treatment at a given point in time versus no treatment at that point in time, implying that 
the treatment may take place at some later point in time. Thus, the control group involves both individuals who never participate and those who defer participation. This effect is commonly referred to as the effect of training versus waiting (Sianesi, 2004). In order to mimic this parameter, we simulate the training status of the actual trainees imposing that they postpone participation at least one quarter beyond their observed true program start. This entails the possibility that the simulated training dummies are zero during all quarters for some individuals. Table 7 in Appendix $\mathrm{C}$ depicts the actual and the simulated participation rates. From the last row of table 7 , it can be seen that under the simulated waiting scenario only $68.7 \%$ of the original participants ever enrol into training. We calculate the effect of training versus waiting as the difference between the simulated actual employment rates of the trainees and their simulated employment rates under the waiting scenario.

— Insert figure 6 about here. -

The results are displayed in Figure $6 .^{24}$ There are negative lock-in effects of similar magnitude and length as for the classical effect of training in figure 5. In the quarter in which the program starts, participants in training have a seven to 14 ppoints lower probability to be in employment than compared to the situation of not yet starting a program. After about four to five quarters $(\pi=t-s=3,4)$, the treatment effects turn positive and then increase further during the subsequent quarters. In quarter ten since program start $(\pi=t-s=9)$, they lie in the range of 7 to 15 ppoints. This is about a third less than in the case of a pure no-training control group.

Based on our model estimates, the estimated effect for treatment versus waiting underestimates the causal (classical) treatment effect in the medium and long run. This finding is due to the fact that control persons who obtain training in the near future also experience positive treatment effects in the medium and long run.

\subsection{Treatment Effects for Different Planned Training Dura- tions}

Here, we use our model estimates to analyze how treatment effects vary with the planned program duration. Typically, participation in training decreases the exit

\footnotetext{
${ }^{24}$ The corresponding numbers are given in table 8 in Appendix C.
} 
rates from unemployment between the start and the end date of a program compared to a situation of no participation (lock-in effect). The size of the reduction in job finding probabilities may change over the course of treatment. If job finding efforts increase towards the end of the program, the time until the scheduled end date has a negative effect on exits from unemployment. In a mechanical sense, a shorter planned enrollment length should therefore be associated with a shorter and less pronounced lock-in period. However, it is unclear whether such an advantage in the short run persists over time. If, by administering shorter programs, one could decrease the lock-in effect without reducing the long-run employment gains, policy makers would be advised to shorten planned durations.

Similar to above, we simulate the training and employment histories of the subsample of training participants that result after fixing the planned program duration to a prespecified value. Specifically, we consider planned program durations of one, two, three, and four quarters. We then evaluate the effect of participating in a program scheduled over one, three, and four quarters, respectively, as opposed to two quarters, the median of planned duration. Tables 9 to 12 in Appendix C show the simulated participation and employment rates associated with different planned program durations. Note that the simulated realized program duration can be shorter or longer than the planned one. However, the tables suggest that there is a strong positive correlation between planned and realized program durations.

— Insert figure 7 about here. -

- Insert figure 8 about here. -

— Insert figure 9 about here. -

Figure 7 displays the treatment effects associated with a planned duration of one versus two quarters. ${ }^{25}$ The gains of a shorter participation are small and only transient. In the third quarter after program start $(\pi=t-s=2)$, the employment rate is between one and two ppoints higher. In the medium and long run, those attending programs with a scheduled length of two quarters fare better, exhibiting employment rates that are consistently higher by three to five ppoints. A similar

\footnotetext{
${ }^{25}$ The corresponding numbers are given in table 13 in Appendix C.
} 
pattern emerges when comparing programs with a scheduled length of three and four quarters, respectively, with those planned to last two quarters, cf. figures 8 and $9 .{ }^{26}$ Trainees attending longer programs are only slightly worse off during the additional quarters they are supposed to be in the program. After the scheduled end of the longer program, they have consistently higher employment rates than compared to the benchmark case of a six-month program. Indeed, compared to a planned duration of two quarters, the employment rates associated with attending a nine-month program are four to six ppoints higher and those associated with attending a one-year program are six to eleven ppoints higher.

\section{Conclusions}

Training programs are an important part of active labor market policies of many advanced countries. This paper examines the effects of training incidence and duration on labor market transitions in discrete time. We estimate a dynamic random effects probit model including an employment and a participation equation based on large administrative data for Germany. The participation equation models the start of training as well as its end accounting for endogenous dropout. We control for selection on unobservables by allowing the random effects of both equations to be correlated. We account for time and duration dependence as well as for various forms of effect heterogeneity in a flexible way. Using Bayesian Markov Chain Monte Carlo (MCMC) methods, we estimate the posterior distribution of the model parameters, including the individual random effects. The analysis is separately done for West and East Germany and for males and females. Because of the complexity and the dynamic nature of our model, we simulate different treatment effects of interest using the estimated distribution of the coefficients and the individual specific effects from the sequence of MCMC iterations.

Our findings imply positive effects of training on the employment probability emerging three to four quarters after program start in all four subsamples considered. Ten quarters after program start, the effect of treatment on unconditional employment rates for the treated individuals lies between 12 and 21 percentage points (ppoints). The effects are higher for women than for men and higher in West Germany than

${ }^{26}$ The corresponding numbers are given in tables 14 and 15 in Appendix C. 
in East Germany. Our estimation approach allows us to estimate various other treatment effects of interest.

Similar to the recent literature applying sequential matching techniques to estimate the effect of treatment at a given date versus not at that date but possibly later (cf. Sianesi, 2004), we simulate the effect of training versus waiting. Based on our model estimates, we find that the effect of treatment versus waiting underestimates the treatment effect of training versus no training in the medium and long run by about a third.

Finally, we use our estimates to analyze how training effects vary with planned program duration. Longer planned enrollment lengths of three and four quarters, respectively, as opposed to just two quarters lead to an increase in employment rates by four to six ppoints and six to eleven ppoints, respectively, in the medium and long run. This suggests that, on average, the higher costs of longer training programs translate into higher long-run employment gains.

\section{References}

Abbring, J.H. and J.J. Heckman (2007). "Econometric Evaluation of Social Programs, Part III: Distributional Treatment Effects, Dynamic Treatment Effects, Dynamic Discrete Choice, and General Equilibrium Policy Evaluation." In J.J. Heckman and E.E. Leamer (eds), Handbook of Econometrics, Vol. 6B. Amsterdam: Elsevier Science, ch. 72, 5145-5303.

Abbring, J.H. and G.J. van den Berg (2003). "The Nonparametric Identification of Treatment Effects in Duration Models." Econometrica, 71, 1491-1517.

Abbring, J.H. and G.J. van den Berg (2004). "Analyzing the Effect of Dynamically Assigned Treatments using Duration Models, Binary Treatment Models, and Panel Data Models." Empirical Economics, 29, 5-20.

Abbring, J.H. and G.J. van den Berg (2005). "Social Experiments and Instrumental Variables with Duration Outcomes." Tinbergen Institute Discussion Paper TI $2005-047 / 3$.

Albert, J.H. and S. Chib (1993). "Bayesian Analysis of Binary and Polychotomous Response Data." The Journal of the American Statistical Association, 88, 669-679. 
Bergemann, A., B. Fitzenberger, and S. Speckesser (2009). "Evaluating the Dynamic Employment Effects of Training Programs in East Germany Using Conditional Difference-in-Differences." Journal of Applied Econometrics, 24, 797823.

Biewen, M., B. Fitzenberger, A. Osikominu, and M. Waller (2007). "Which Program for Whom? Evidence on the Comparative Effectiveness of Public Sponsored Training Programs in Germany." IZA Discussion Paper No. 2885, Bonn.

Buchinsky, M., D. Fougère, F. Kramarz, and R. Tchernis (2010). "Interfirm Mobility, Wages, and the Returns to Seniority and Experience in the U.S." Review of Economic Studies, 77, 972-1001.

Bundesanstalt für Arbeit (2001). Arbeitsstatistik 2000 - Jahreszahlen. Nürnberg.

Bundesagentur für Arbeit (2006). Arbeitsstatistik 2005 - Jahreszahlen. Nürnberg.

Bundesagentur für Arbeit (2007, 2008). Arbeitsmarkt 2006, 200\%." Nürnberg.

Card, D., J. Kluve, and A. Weber (2009). "Active Labor Market Policy Evaluations: A Meta-Analysis." CESifo Working Paper No. 2570, Munich.

Chib, S. (2001). "Markov Chain Monte Carlo Methods: Computation and Inference." In J.J. Heckman and E.E. Leamer (eds.): Handbook of Econometrics, Vol. 5, Amsterdam: Elsevier Science, ch. 57, 3569-3649.

Chib, S. and B.H. Hamilton (2002). "Semiparametric Bayes Analysis of Longitudinal Data Treatment Models." Journal of Econometrics, 110, 67-89.

Chib, S. and L. Jacobi (2007). "Modeling and Calculating the Effect of Treatment at Baseline from Panel Outcomes." Journal of Econometrics, 140, 781-801.

Dyke, A., C.J. Heinrich, P.R. Mueser, K.R. Troske, and K.-S. Jeon (2006). "The Effects of Welfare-to-Work Program Activities on Labor Market Outcomes." Journal of Labor Economics, 24, 567-607.

Flores-Lagunes A., A. Gonzalez, and T.C. Neumann (2009). "Estimating the Effects of Length of Exposure to a Training Program: The Case of Job Corps." Mimeo, University of Florida.

Fredriksson, P. and P. Johansson (2008). "Dynamic Treatment Assignment: The Consequences for Evaluations Using Observational Data." Journal of Business and Economic Statistics, 26, 435-445. 
Heckman, J.J., R.J. LaLonde, and J.A. Smith (1999). "The Economics and Econometrics of Active Labor Market Programs." In: O. Ashenfelter and D. Card (eds.), Handbook of Labor Economics, Vol. 3 A, Amsterdam: Elsevier Science, ch. 31, 1865-2097.

Heckman, J.J. and S. Navarro (2007). "Dynamic Discrete Choice and Dynamic Treatment Effects." Journal of Econometrics, 136, 341-396.

Horny, G., R. Mendes, and G.J. van den Berg (2009). "Job Durations and Firm Specific Effects: MCMC Estimation with Longitudinal Employer-Employee Data." IZA Discussion Paper No. 3992, Bonn.

Hujer, R., S.L. Thomsen, and C. Zeiss (2006): "The Effects of Vocational Training Programmes on the Duration of Unemployment in Eastern Germany." AStA Advances in Statistical Analysis, 90, 299-321.

Hirano, K. and G.W. Imbens (2004). "The Propensity Score with Continuous Treatments." In A. Gelman and X.L. Meng (eds.), Applied Bayesian Modeling and Causal Inference from Incomplete-Data Perspectives. West Sussex: Wiley, 73-84.

Imai, K. and D.A. van Dijk (2004). "Causal Inference With General Treatment Regimes: Generalizing the Propensity Score." Journal of the American Statistical Association, 99, 854-866.

Imbens, G. (2000). "The Role of the Propensity Score in Estimating Dose-Response Functions." Biometrika, 87, 706-710.

Kluve, J., H. Schneider, A. Uhlendorff and Z. Zhao (2007). "Evaluating Continuous Training Programs Using the Generalized Propensity Score." IZA Discussion Paper No. 3255, Bonn.

Kühnlein, G. and B. Klein (2003). "Bildungsgutscheine - mehr Eigenverantwortung, mehr Markt, mehr Effizienz? - Erfahrungen bei der Neuausrichtung der beruflichen Weiterbildung." Arbeitspapier Band 74, Hans-Böckler-Stiftung.

Lechner, M. (2001). "Identification and Estimation of Causal Effects of Multiple Treatments Under the Conditional Independence Assumption." In M. Lechner and F. Pfeiffer (eds.), Econometric Evaluation of Labour Market Policies. Heidelberg, New York: Physica, 43-58.

Lechner, M., R. Miquel, and C. Wunsch (2009). "Long-Run Effects of Public Sector Sponsored Training in West Germany." Journal of the European Economic Association, forthcoming. 
Martin, John P., and David Grubb (2001). "What Works for Whom: A Review of OECD Countries' Experiences with Active Labour Market Policies." Swedish Economic Policy Review, 8, 9-56.

OECD (2007). OECD Employment Outlook. Paris.

Osikominu, A. (2009). "Quick Job Entry or Long-Term Human Capital Development? The Dynamic Effects of Alternative Training Schemes." IZA Discussion Paper No. 4638.

Plaßmann, G. (2002). "Der Einfluss der Arbeitslosenversicherung auf die Arbeitslosigkeit in Deutschland." Beiträge zur Arbeitsmarkt- und Berufsforschung, BeitrAB 255, Nürnberg.

Richardson, K. and G.J. van den Berg (2008). "Duration dependence versus unobserved heterogeneity in treatment effects: Swedish labor market training and the transition rate to employment." IFAU Working Paper 2008:7.

Roy, A.D. (1951). "Some Thoughts on the Distribution of Earnings." Oxford Economic Papers, 3, 135-146.

Rubin, D.B. (1974). "Estimating Causal Effects of Treatments in Randomized and Nonrandomized Studies." Journal of Educational Psychology, 66, 688-701.

Schneider, H., K. Brenke, D. Hess, L. Kaiser, J. Steinwedel and A. Uhlendorff (2006). "Evaluation der Maßnahmen zur Umsetzung der Vorschläge der HartzKommission - Modul 1b: Förderung beruflicher Weiterbildung und Transferleistungen." IZA Research Report No. 7, Bonn.

Sianesi, B. (2004). "An Evaluation of the Swedish System of Active Labor Market Programs in the 1990s." Review of Economics and Statistics, 86, 133-155.

Train, K. (2003). Discrete Choice Methods with Simulation. Cambridge: Cambridge University Press.

Troske, K.R., and A. Voicu (2010). "Joint Estimation of Sequential Labor Force and Fertility Decisions Using Markov Chain Monte Carlo Techniques." Labour Economics, 17, 150-169.

Waller, M. (2008). "On the Importance of Correcting Reported End Dates of Labor Market Programs." Journal of Applied Social Science Studies, 128, 213-236.

Waller, M. (2009). Many Dropouts? Never Mind! - Employment Prospects of Dropouts from Training Programs, CDSE Mannheim Discussion Paper No. 63. 
Zeger, S. and M. Karim (1991). "Generalized linear models with random effects: a Gibbs sampling approach." Journal of the American Statistical Association, $86,79-86$.

\section{Figures}

Figure 1: Entries into Training Programs in West and East Germany (in 1000)
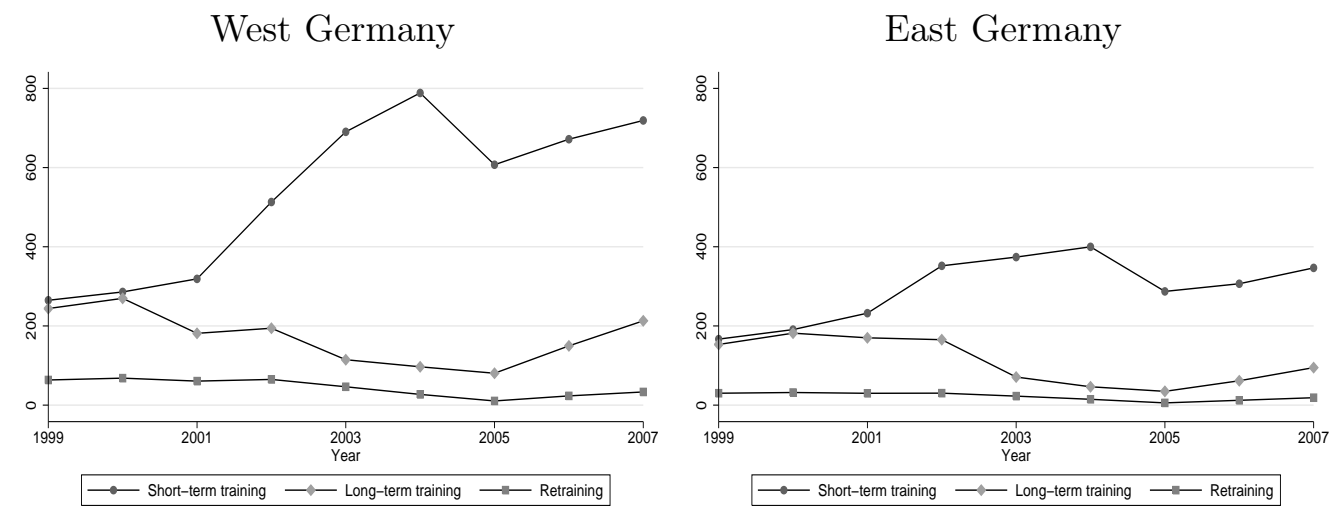

Source: Bundesagentur für Arbeit (2001, 2006, 2007, 2008); own calculations. 
Figure 2: Planned and Realized Training Durations

West German Men

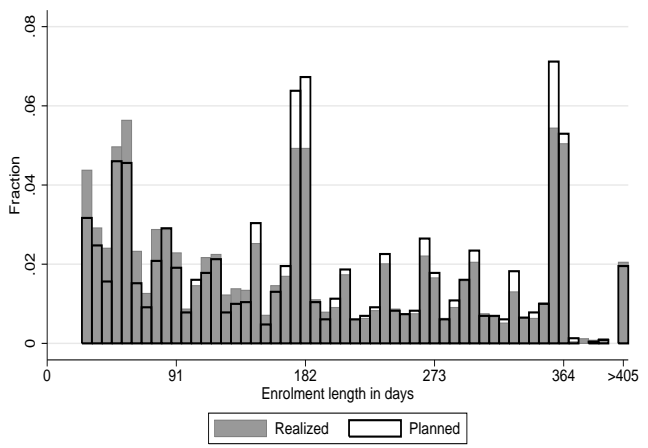

East German Men

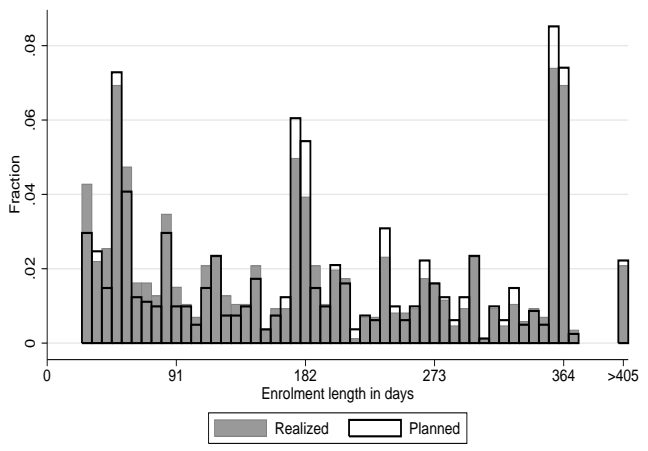

West German Women

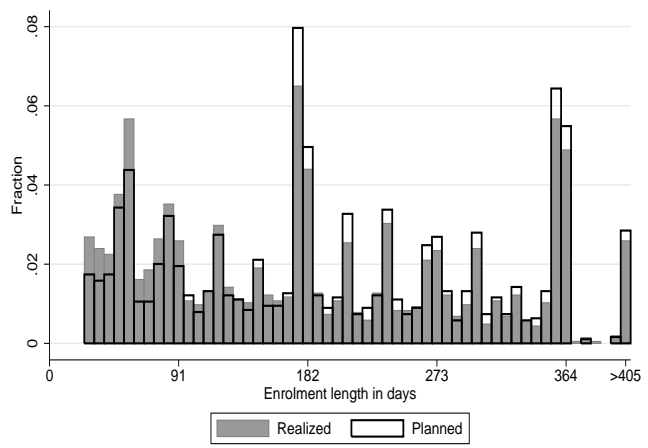

East German Women

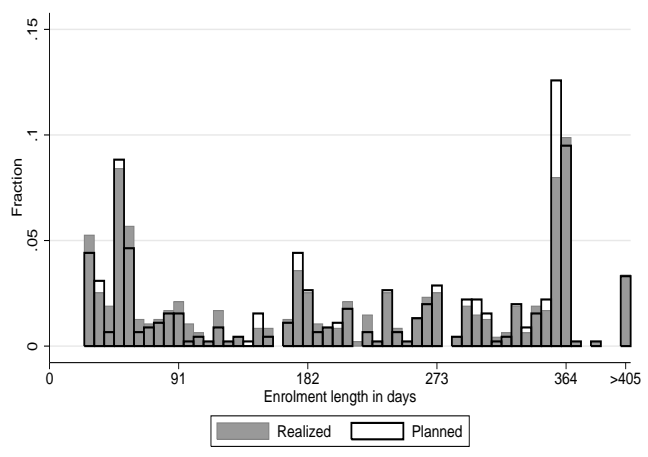


Figure 3: Employment and Participation Rates over Time

West German Men

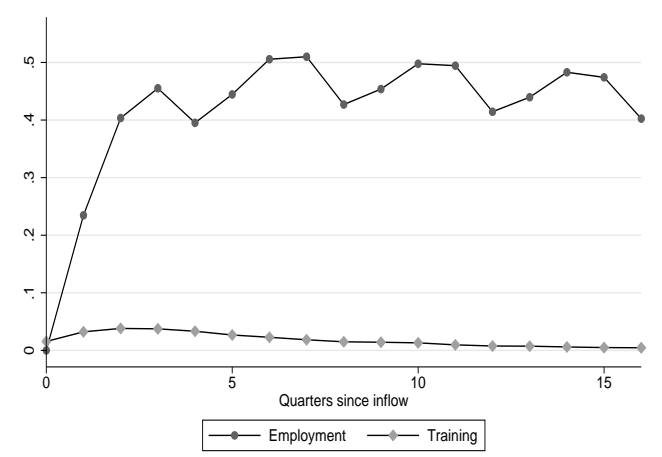

East German Men

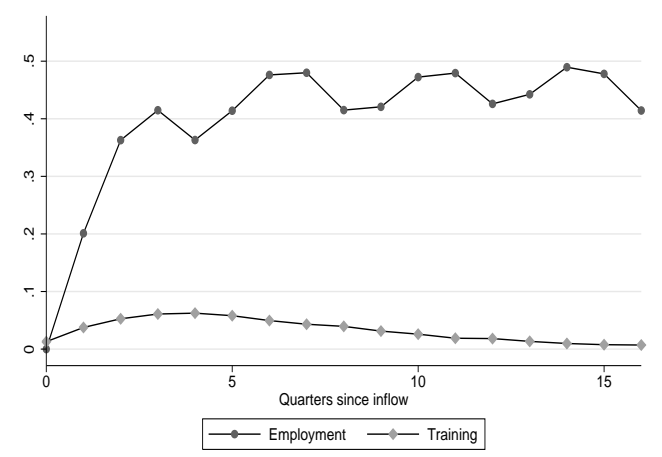

West German Women

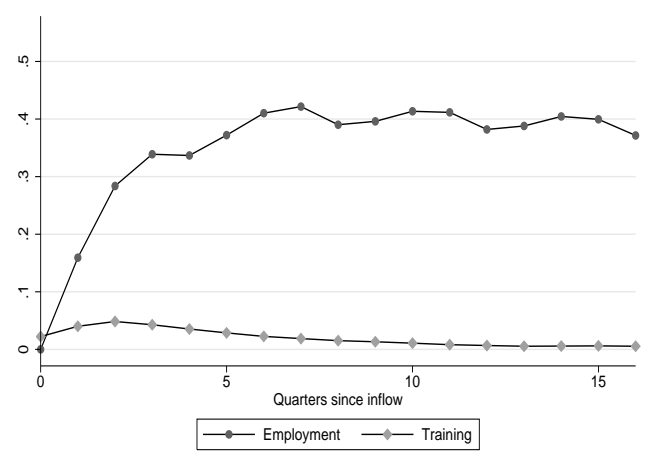

East German Women

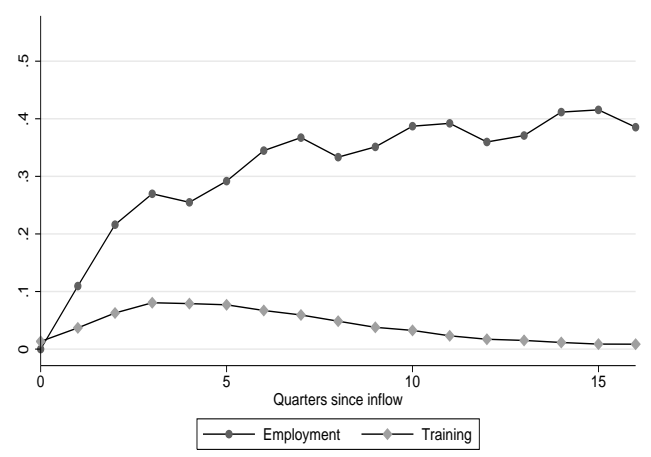


Figure 4: Raw Treatment and Nontreatment Employment Rates

West German Men

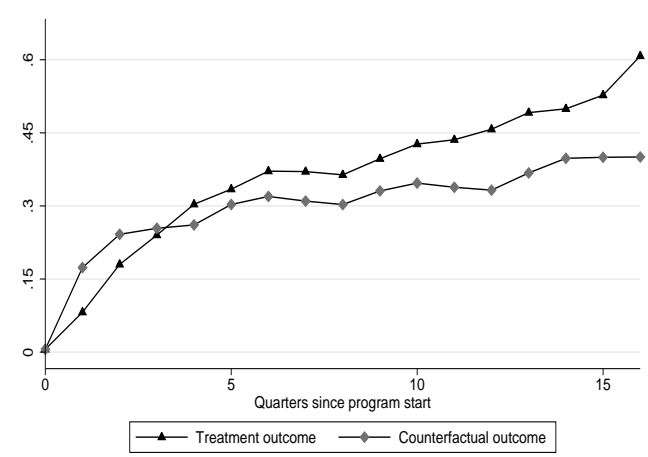

East German Men

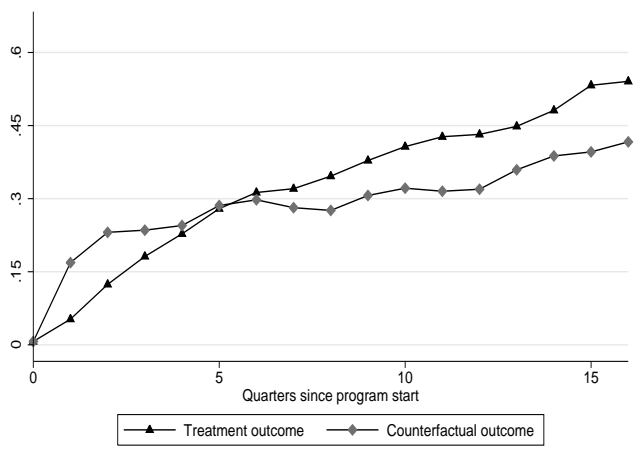

West German Women

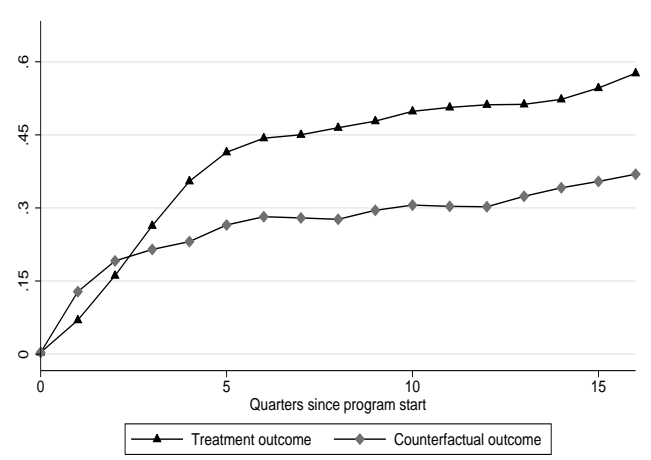

East German Women

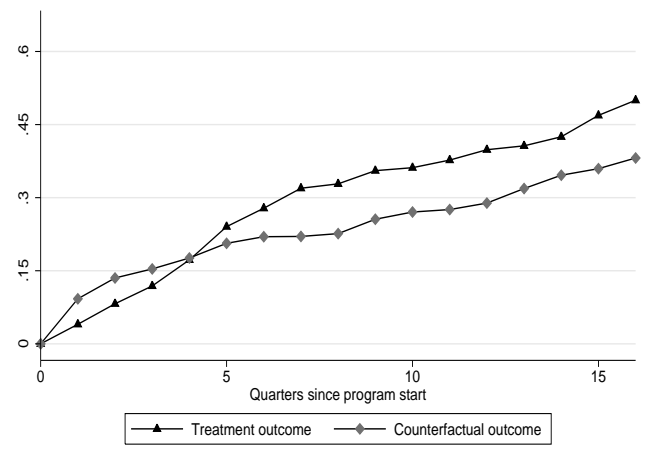

Notes: Raw estimates of the treatment effect on the treated, where treated and controls are aligned in the time dimension only. In particular, treated and nontreated individuals are matched on the calendar quarter of their first inflow and elapsed unemployment duration in the current spell. No adjustments are made for other potential sources of selection bias. 
Figure 5: Classical Average Treatment Effect on the Treated

West German Men

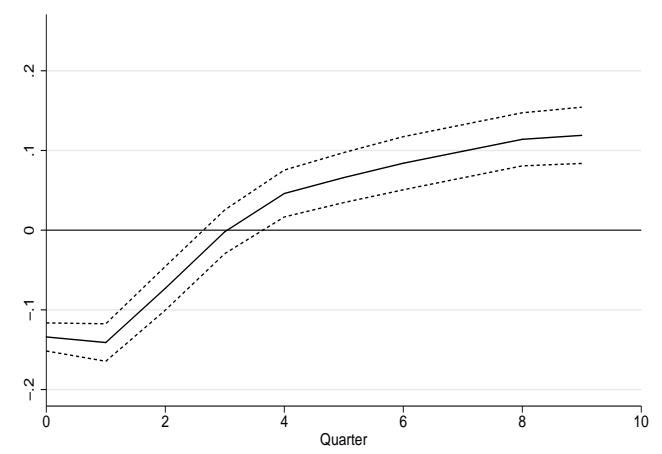

East German Men

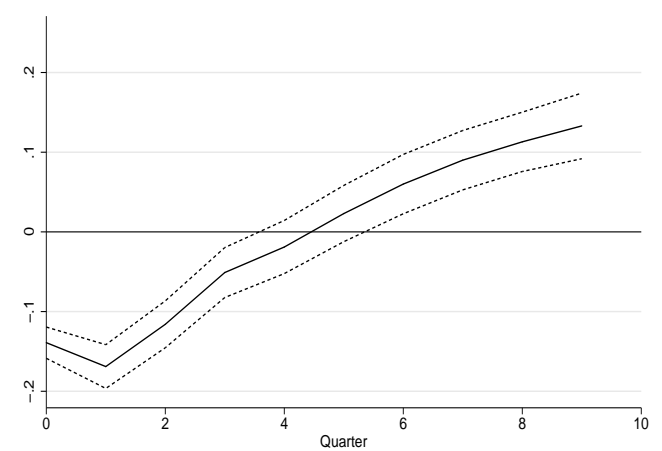

West German Women

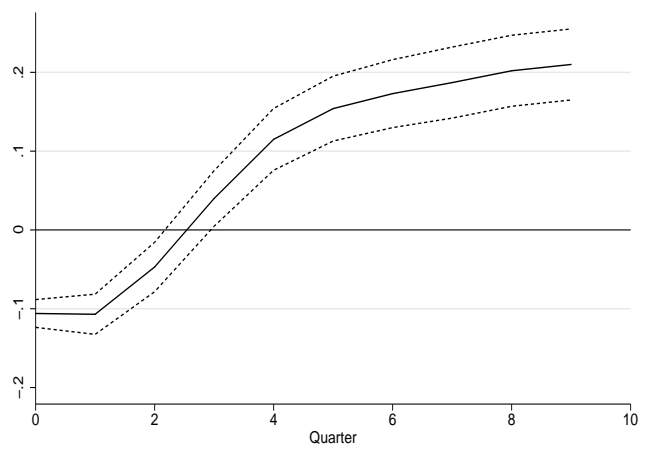

East German Women

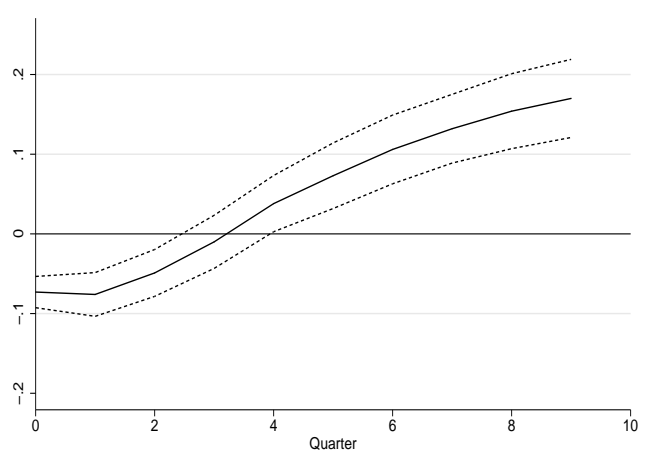

Notes: Difference in employment rates measured on the ordinate, post-treatment quarters on the abscissa. 
Figure 6: ATT of Training versus Waiting

West German Men

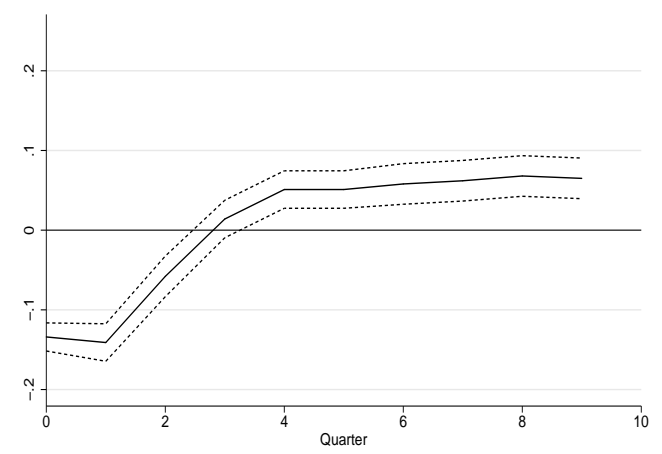

East German Men

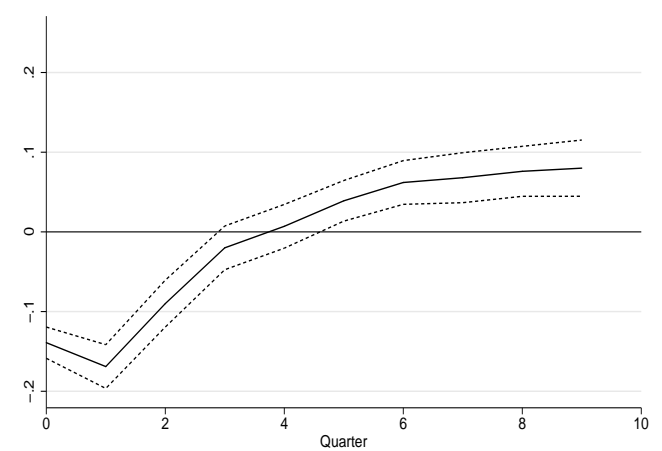

West German Women

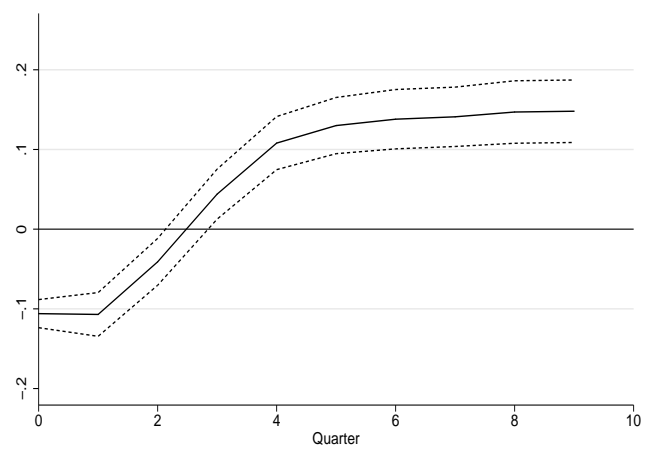

East German Women

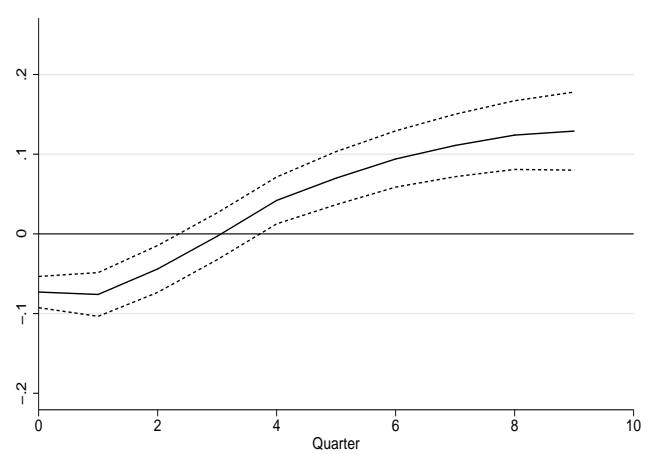

Notes: Difference in employment rates measured on the ordinate, post-treatment quarters on the abscissa. 
Figure 7: ATT of Attending a Program Scheduled for One versus Two Quarters

West German Men

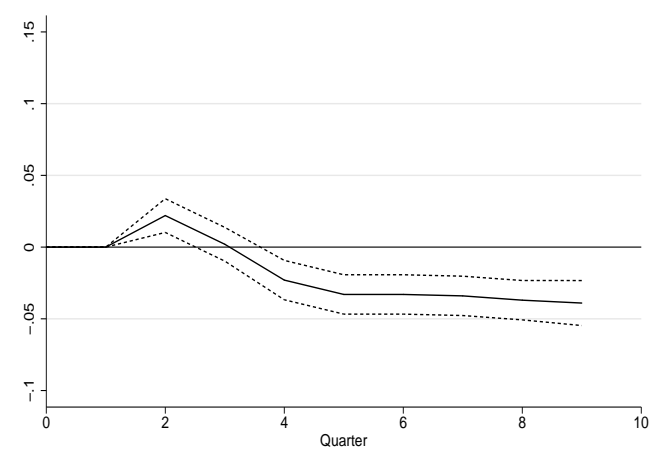

East German Men

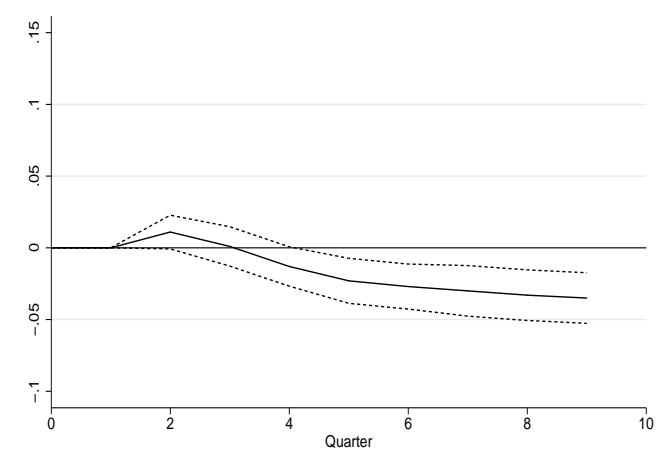

West German Women

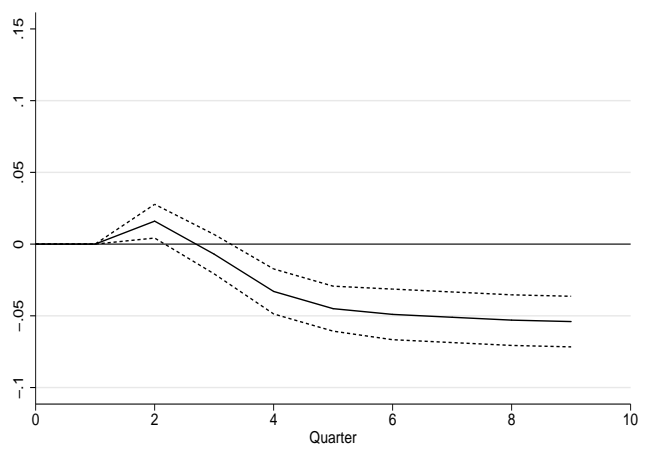

East German Women

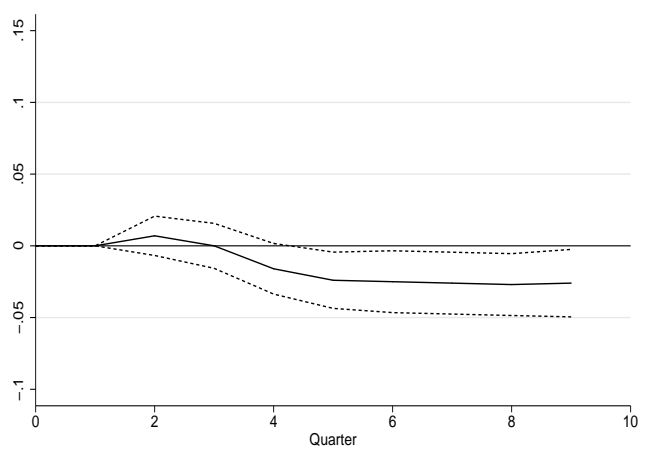

Notes: Difference in employment rates measured on the ordinate, post-treatment quarters on the abscissa. 
Figure 8: ATT of Attending a Program Scheduled for Three versus Two Quarters

West German Men

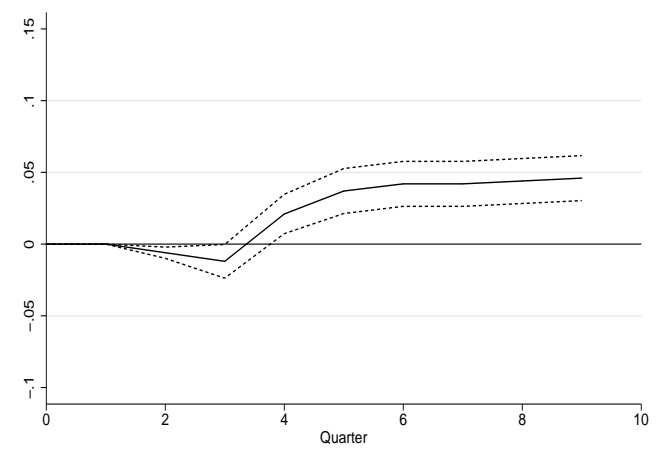

East German Men

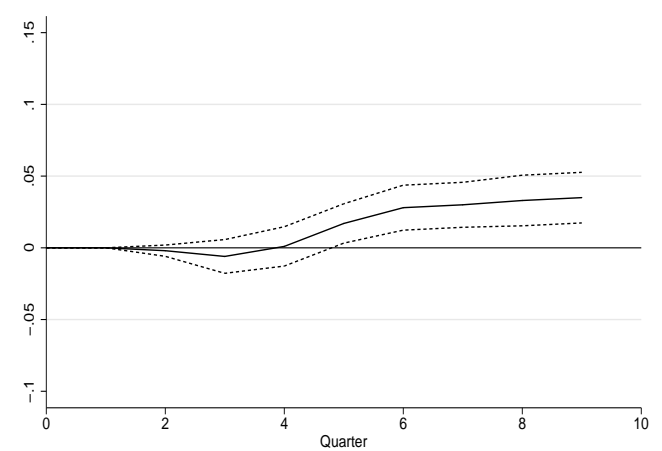

West German Women

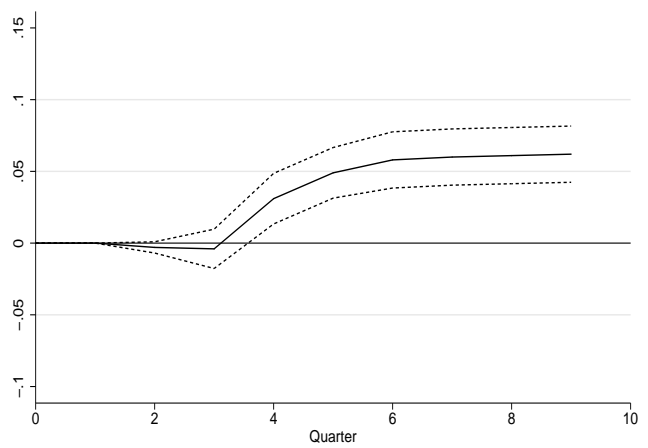

East German Women

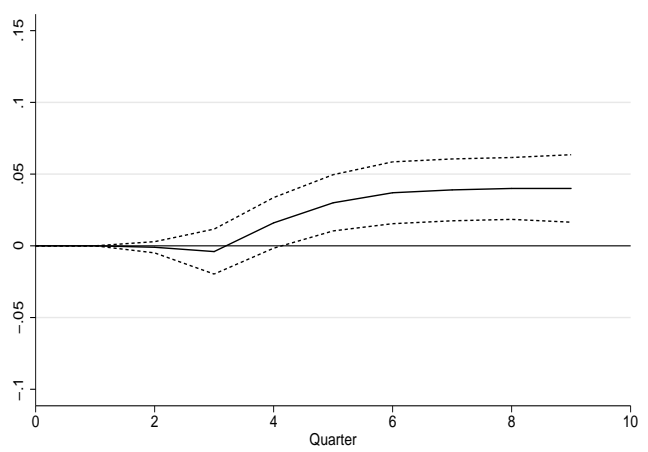

Notes: Difference in employment rates measured on the ordinate, post-treatment quarters on the abscissa. 
Figure 9: ATT of Attending a Program Scheduled for Four versus Two Quarters

West German Men

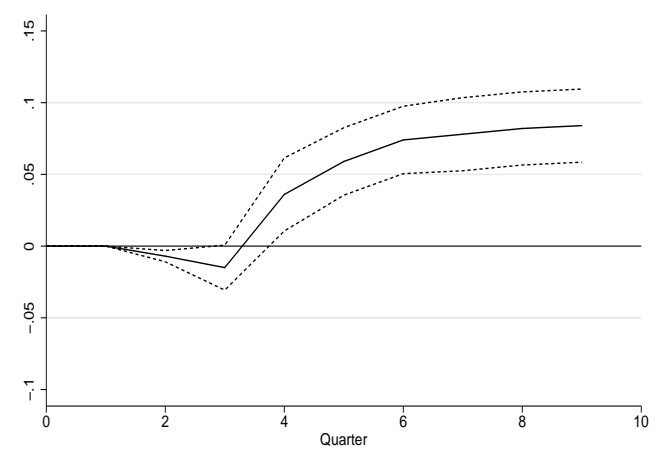

East German Men

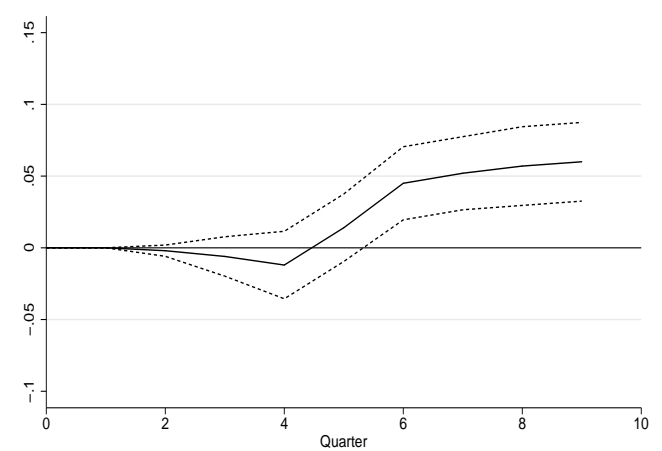

West German Women

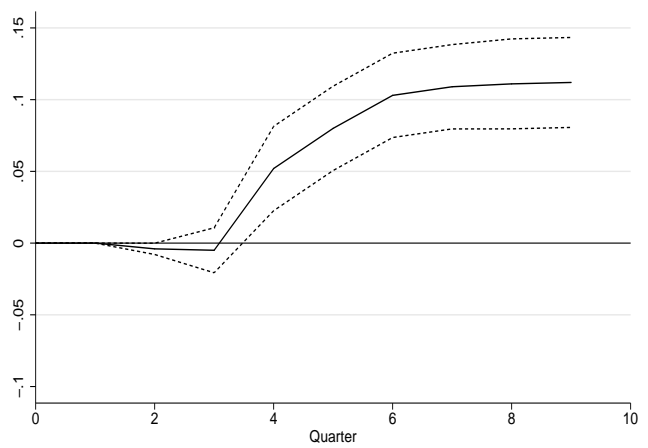

East German Women

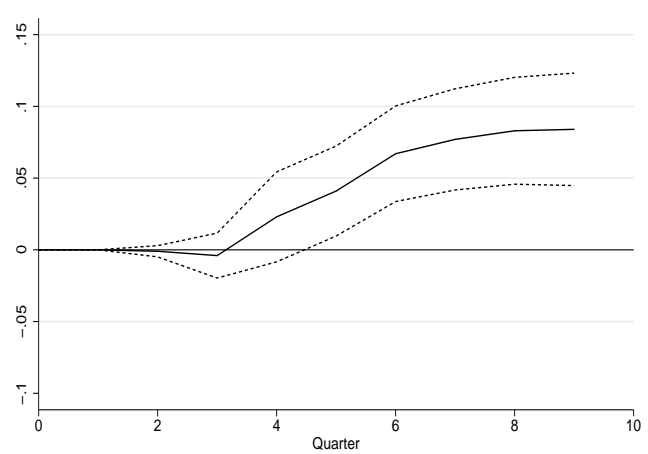

Notes: Difference in employment rates measured on the ordinate, post-treatment quarters on the abscissa. 


\section{Tables}

Table 1: Descriptive Statistics

\begin{tabular}{l|llll}
\hline & $\begin{array}{l}\text { Male, } \\
\text { West }\end{array}$ & $\begin{array}{l}\text { Female, } \\
\text { West }\end{array}$ & $\begin{array}{l}\text { Male, } \\
\text { East }\end{array}$ & $\begin{array}{l}\text { Female, } \\
\text { East }\end{array}$ \\
\hline Individuals & 16,317 & 12,328 & 8,737 & 4,869 \\
Quarters per Person & 14.7 & 15.3 & 13.2 & 13.5 \\
Quarters Employed p. P. & 6.0 & 5.2 & 5.1 & 4.0 \\
Quarters Unemployed p. P. & 8.7 & 10.1 & 8.2 & 9.5 \\
Quarters in Training p. P. & 0.27 & 0.31 & 0.45 & 0.56 \\
Employment Spells p. P. & 1.21 & 0.85 & 1.06 & 0.74 \\
Unemployment Spells p. P. & 1.89 & 1.53 & 1.78 & 1.48 \\
Training Spells p. P. & 0.11 & 0.12 & 0.16 & 0.19 \\
\hline
\end{tabular}

Table 2: Employment Rate and Number of Participants Still Observed Aligned to Start of Program

\begin{tabular}{|c|c|c|c|c|c|c|c|c|c|c|c|c|}
\hline 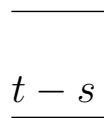 & $\begin{array}{l}\text { Male } \\
\bar{E}_{t-s}\end{array}$ & $\begin{array}{l}\text { West } \\
\hat{E}_{t-s}\end{array}$ & $N_{t-s}$ & $\begin{array}{l}\text { Fema } \\
\bar{E}_{t-s}\end{array}$ & $\begin{array}{l}\text { e West } \\
\hat{E}_{t-s}\end{array}$ & $N_{t-s}$ & $\begin{array}{l}\text { Male } \\
\bar{E}_{t-s}\end{array}$ & $\begin{array}{l}\text { East } \\
\hat{E}_{t-s}\end{array}$ & $N_{t-s}$ & $\begin{array}{l}\text { Fema } \\
\bar{E}_{t-s}\end{array}$ & $\begin{array}{c}\text { le East } \\
\hat{E}_{t-s}\end{array}$ & $N_{t-s}$ \\
\hline r & 0.000 & $0.000^{*}$ & 1740 & 0.000 & $0.000^{*}$ & 1431 & 0.000 & $0.000^{*}$ & 1300 & 0.000 & $0.000^{*}$ & 848 \\
\hline & 079 & $0.079^{*}$ & 1740 & 0.070 & $0.070^{*}$ & 1431 & 0.048 & 0.0 & 1300 & 39 & $0.039^{*}$ & \\
\hline & 179 & 0.177 & 1721 & 0.16 & 0.165 & 1411 & 0.120 & 0.1 & 1290 & | & 0.078 & 840 \\
\hline & 39 & 0.244 & 1696 & 64 & 0.267 & 1385 & 78 & 0 . & 1282 & & 21 & 34 \\
\hline & 302 & 0.301 & 166 & 0.3 & 0.355 & 1366 & 0.226 & 0.218 & 1265 & 0.172 & 0.185 & 825 \\
\hline & 34 & 0.346 & 1623 & 5 & 12 & 338 & 78 & 0.284 & 1229 & 40 & .239 & 16 \\
\hline & 371 & 0.370 & 15 & 0.442 & 0.440 & 1316 & 0.311 & 0.320 & 1201 & 0.279 & 0.274 & 795 \\
\hline & 1 & 0.377 & 15 & 0.450 & 0.454 & 1291 & 18 & 0.335 & 1159 & 0.320 & 0.300 & 765 \\
\hline & 364 & 0.387 & 146 & 0.464 & 0.468 & 1253 & 0.345 & 0.355 & 1106 & 0.329 & 0.330 & 741 \\
\hline & 0.396 & 0.405 & 1393 & 0.478 & 0.481 & 1213 & 378 & 0.391 & 1039 & 0.356 & 0.355 & 710 \\
\hline
\end{tabular}

Notes: $t-s$ denotes the quarters elapsed since program start, and $\bar{E}_{t-s}$ the sample mean of the employment dummy in quarter $t-s . \hat{E}_{t-s}$ is the mean of the employment dummy as predicted using the simulation strategy (prediction of treatment outcomes).

* Observed value is taken for the first period. 
Table 3: Differences Between Treated and Untreated in Transition Rates out of Non-Employment

\begin{tabular}{l|ll|ll|ll|ll}
\hline & \multicolumn{2}{|c|}{ Male West } & \multicolumn{2}{|c|}{ Female West } & \multicolumn{2}{c|}{ Male East } & \multicolumn{2}{c}{ Female East } \\
$t-s$ & Mean & SD & Mean & SD & Mean & SD & Mean & SD \\
\hline 0 & -0.134 & 0.009 & -0.106 & 0.009 & -0.139 & 0.010 & -0.073 & 0.010 \\
1 & -0.058 & 0.010 & -0.034 & 0.010 & -0.083 & 0.011 & -0.027 & 0.010 \\
2 & 0.011 & 0.009 & 0.026 & 0.010 & -0.016 & 0.010 & -0.006 & 0.009 \\
3 & 0.039 & 0.008 & 0.071 & 0.009 & 0.009 & 0.009 & 0.013 & 0.008 \\
4 & 0.049 & 0.009 & 0.089 & 0.010 & 0.002 & 0.010 & 0.040 & 0.010 \\
5 & 0.023 & 0.009 & 0.064 & 0.011 & 0.028 & 0.011 & 0.034 & 0.011 \\
6 & 0.017 & 0.010 & 0.043 & 0.011 & 0.027 & 0.011 & 0.038 & 0.012 \\
7 & 0.013 & 0.009 & 0.034 & 0.011 & 0.023 & 0.010 & 0.031 & 0.011 \\
8 & 0.012 & 0.009 & 0.035 & 0.011 & 0.024 & 0.011 & 0.034 & 0.013 \\
9 & 0.006 & 0.010 & 0.028 & 0.011 & 0.029 & 0.013 & 0.028 & 0.013 \\
\hline
\end{tabular}

Notes: $t-s$ denotes the quarters elapsed since program start.

Table 4: Differences Between Treated and Untreated in Transition Rates out of Employment

\begin{tabular}{l|ll|ll|ll|ll}
\hline & \multicolumn{2}{|c|}{ Male West } & \multicolumn{2}{|c|}{ Female West } & \multicolumn{2}{c|}{ Male East } & \multicolumn{2}{c}{ Female East } \\
$t-s$ & Mean & SD & Mean & SD & Mean & SD & Mean & SD \\
\hline 2 & -0.085 & 0.037 & -0.089 & 0.040 & -0.125 & 0.052 & -0.170 & 0.073 \\
3 & -0.072 & 0.028 & -0.095 & 0.028 & -0.106 & 0.038 & -0.143 & 0.059 \\
4 & -0.048 & 0.024 & -0.071 & 0.025 & -0.074 & 0.031 & -0.096 & 0.049 \\
5 & -0.056 & 0.020 & -0.058 & 0.021 & -0.073 & 0.026 & -0.095 & 0.041 \\
6 & -0.073 & 0.019 & -0.058 & 0.020 & -0.091 & 0.025 & -0.101 & 0.039 \\
7 & -0.088 & 0.019 & -0.066 & 0.020 & -0.106 & 0.026 & -0.107 & 0.036 \\
8 & -0.091 & 0.020 & -0.068 & 0.020 & -0.103 & 0.025 & -0.099 & 0.036 \\
9 & -0.085 & 0.019 & -0.062 & 0.019 & -0.092 & 0.025 & -0.091 & 0.034 \\
\hline
\end{tabular}

Notes: $t-s$ denotes the quarters elapsed since program start. 


\section{Appendix}

\section{A Detailed Information on the Data}

This study uses data from the IEBS Version 4.02. A German description of the IEBS Version 3.01 can be found in Zimmermann et al. (2007). Information in English can be found on the website of the Research Data Center of the Federal Employment Agency (http://fdz.iab.de/en.aspx). The website also describes the conditions under which researchers may obtain access to the IEBS.

The first of the four administrative data sources included in the IEBS, the IAB Employment History, consists of social insurance register data for employees subject to contributions to the public social security system. It covers the time period from 1990 to 2004. The main feature of these data is detailed daily information on the employment status of each recorded individual. For each employment spell, in addition to start and end dates, data from the Employment History contain information on personal as well as job and firm characteristics such as wage, industry or occupation.

The IAB Benefit Recipient History, the second data source, includes daily spells of unemployment benefit, unemployment assistance and subsistence allowance payments the individuals received between January 1990 and June 2005. In addition to the sort of the payment and the start and end dates of periods of transfer receipt the spells contain further information like sanctions, periods of disqualification from benefit receipt and personal characteristics. Furthermore, the information in the Employment and the Benefit Recipient History allows one to calculate the individual entitlement periods to unemployment benefits. ${ }^{27}$

The third data source included in the IEBS is the so-called Data on Job Search Originating from the Applicants Pool Database, which contains rich information on individuals searching for jobs. It contains all the records starting January 2000 to June 2005 and partly also those beginning before 2000 if the person in question keeps the same client number throughout. The database includes a rich variety of information on personal characteristics (in particular education, family status and health condition), information related to placement fields (e.g. qualification and experience in the target profession), and regional information.

The Participants-in-Measures Data, the fourth data source, contains diverse information on participation in public sector sponsored labor market programs, for example training programs, job-creation measures, integration subsidies, business start-up allowances covering the period January 2000 to July 2005. Comparing the

\footnotetext{
${ }^{27}$ For the calculation of the claims, the present study relies on Plaßmann (2002) that contains a summary of the different regulations.
} 
entries into different programs in 1999 with the figures for later years shows that information on programs starting in 1999 seems to be already complete for most active labor market programs. Furthermore, this database allows to distinguish subsidized employment in the context of active labor market policy from regular employment. Similar to the other sources, information comes in the form of spells indicating the start and end dates at the daily level, the type of the program as well as additional information on the program such as the planned end date or if the program ends with a certificate.

\section{B Algorithm for the MCMC Estimation}

The posterior distribution combines the likelihood and the priors. We set the following independent priors: the prior distributions of the coefficients $\boldsymbol{\eta}_{E}$ are given by independent normal priors with distribution $\mathcal{N}\left(b_{E, 0}, B_{E, 0}\right) . \mathcal{N}(\cdot)$ denotes the normal distribution. Setting very large values for the variance $B_{E, 0}$, we use extremely diffuse priors. The same is done for the elements of the coefficient vector $\boldsymbol{\eta}_{Q}$, whose prior distributions are given by $\mathcal{N}\left(b_{Q, 0}, B_{Q, 0}\right)$. The prior distribution of the random effects is $\mathcal{N}(\mathbf{0}, \Sigma)$. The hyperparameter $\Sigma^{-1}$ follows the prior distribution $\mathcal{W}^{-1}\left(H_{0}, h_{0}\right)$, where $H_{0}$ is the inverse scale matrix and $h_{0}$ denotes the degrees of freedom. $\mathcal{W}^{-1}$ denotes the inverse Wishart distribution. In order to set a diffuse prior, we choose a small value for $h_{0}$. The diagonal elements of $H_{0}$ are set to the individual level variances of separate Maximum Likelihood estimations of the two equations multiplied by $h_{0}$, and the off-diagonal elements are set to zero.

- Step 0: Set starting values for the coefficient vectors $\boldsymbol{\eta}_{E}$ and $\boldsymbol{\eta}_{Q}$, the random effects $\left(\alpha_{E, i}, \alpha_{Q, i}\right)$, and the variance covariance matrix of the random effects $\Sigma$.

- Step 1a: Sample $E_{i t}^{*}$ from truncated $\mathcal{N}\left(\boldsymbol{z}_{E, i t} \boldsymbol{\eta}_{E}+\alpha_{E, i}, 1\right)$ with support $(0, \infty)$ if $E_{i t}=1$ and with support $(-\infty, 0]$ if $E_{i t}=0$.

- Step 1b: Sample $Q_{i t}^{*}$ from truncated $\mathcal{N}\left(\boldsymbol{z}_{Q, i t} \boldsymbol{\eta}_{Q}+\alpha_{Q, i}, 1\right)$ with support $(0, \infty)$ if $Q_{i t}=1$ and with support $(-\infty, 0]$ if $Q_{i t}=0$ (using only the time periods in which the training equation is to be estimated).

- Step 2: Sample $\left(\alpha_{E, i}, \alpha_{Q, i}\right)^{\prime}$ from its bivariate normal conditional posterior distribution $\mathcal{N}\left(\boldsymbol{\mu}, V_{\alpha_{i}}\right)$, where $\boldsymbol{\mu}=V_{\alpha_{i}} \cdot\left(\begin{array}{cc}T_{E, i} & 0 \\ 0 & T_{Q, i}\end{array}\right) \cdot\left(\begin{array}{c}\left(\bar{E}_{i}^{*}-\overline{\boldsymbol{z}}_{E, i} \boldsymbol{\eta}_{E}\right) \\ \left(\bar{Q}_{i}^{*}-\overline{\boldsymbol{z}}_{Q, i} \boldsymbol{\eta}_{Q}\right)\end{array}\right)$ and $V_{\alpha_{i}}=\left(\Sigma^{-1}+\left(\begin{array}{cc}T_{E, i} & 0 \\ 0 & T_{Q, i}\end{array}\right)\right)^{-1}$, a bar over a variable denotes its mean across time, $T_{E, i}$ the number of observations for person $i$, and $T_{Q, i}$ the number of observations for person $i$ for which the training equation is to be estimated. 
- Step 3a: Sample the $\boldsymbol{\eta}_{E}$ vector from its multivariate normal conditional posterior distribution $\mathcal{N}\left(M_{E}, V_{E}\right)$, where $M_{E}=V_{E}\left(B_{E, 0}^{-1} b_{E, 0}+\sum_{i=1}^{N} \sum_{t=1}^{T_{E, i}} \boldsymbol{z}_{E, i t}^{\prime}\left(E_{i t}^{*}-\right.\right.$ $\left.\left.\alpha_{E, i}\right)\right)$ and $V_{E}=\left(B_{E, 0}^{-1}+\sum_{i=1}^{N} \sum_{t=1}^{T_{E, i}} \boldsymbol{z}_{E, i t}^{\prime} \boldsymbol{z}_{E, i t}\right)^{-1} . N$ is the number of persons in the data.

- Step 3b: Using only the time periods in which the training equation is to be estimated, sample the $\boldsymbol{\eta}_{Q}$ vector from its multivariate normal conditional posterior distribution $\mathcal{N}\left(M_{Q}, V_{Q}\right)$, where $M_{Q}=V_{Q}\left(B_{Q, 0}^{-1} b_{Q, 0}+\sum_{i=1}^{N} \sum_{t=1}^{T_{Q, i}} \boldsymbol{z}_{Q, i t}^{\prime}\left(Q_{i t}^{*}-\right.\right.$ $\left.\left.\alpha_{Q, i}\right)\right)$ and $V_{Q}=\left(B_{Q, 0}^{-1}+\sum_{i=1}^{N} \sum_{t=1}^{T_{Q, i}} \boldsymbol{z}_{Q, i t}^{\prime} \boldsymbol{z}_{Q, i t}\right)^{-1}$.

- Step 4: Sample $\Sigma^{-1}$ from its conditional posterior distribution

$\mathcal{W}^{-1}\left(\left(\begin{array}{cc}\sum_{i=1}^{N} \alpha_{E, i}^{2} & \sum_{i=1}^{N} \alpha_{E, i} \alpha_{Q, i} \\ \sum_{i=1}^{N} \alpha_{E, i} \alpha_{Q, i} & \sum_{i=1}^{N} \alpha_{Q, i}^{2}\end{array}\right)+H_{0}, N+h_{0}\right)$. Go to Step 1. Always use the current parameter values.

\section{Detailed Estimation Results}

Table 5: Means and Standard Deviations of Parameters from MCMC Estimation

\begin{tabular}{|c|c|c|c|c|c|c|c|c|}
\hline Name & $\begin{array}{l}\text { Male I } \\
\text { Mean } \\
\end{array}$ & $\begin{array}{l}\text { Jest } \\
\text { SD }\end{array}$ & \multicolumn{2}{|c|}{$\begin{array}{l}\text { Female West } \\
\text { Mean SD }\end{array}$} & \multicolumn{2}{|c|}{$\begin{array}{l}\text { Male East } \\
\text { Mean SD }\end{array}$} & \multicolumn{2}{|c|}{$\begin{array}{l}\text { Female East } \\
\text { Mean SD }\end{array}$} \\
\hline \multicolumn{9}{|c|}{ Employment Equation } \\
\hline$\overline{Q_{t-1}}$ & -0.478 & 0.064 & -0.300 & 0.079 & -0.761 & 0.080 & -0.351 & 0.112 \\
\hline \multicolumn{9}{|l|}{$\left[Q_{t-1}=1\right] \times \ldots$} \\
\hline$\ldots\left[Q_{t-2}=1\right] \times\left[Q_{t-3}=0\right]$ & .320 & 0.078 & 0.323 & 0.088 & 0.474 & 0.097 & 0.120 & 0.147 \\
\hline$\ldots\left[Q_{t-3}=1\right] \times\left[Q_{t-4}=0\right]$ & 0.681 & 0.091 & 0.844 & 0.096 & 0.776 & 0.108 & 0.526 & 0.143 \\
\hline$\ldots\left[Q_{t-4}=1\right] \times\left[Q_{t-5}=0\right]$ & 1.222 & 0.111 & 1.418 & 0.120 & 0.834 & 0.124 & 0.996 & 0.148 \\
\hline$\ldots \sum_{j=5}^{6}\left[Q_{t-j}=1 \times Q_{t-7}=0\right]$ & 0.666 & 0.137 & 1.012 & 0.132 & 1.090 & 0.121 & 0.711 & 0.171 \\
\hline$\ldots \sum_{j=7}^{16}\left[Q_{t-j}=1\right]$ & 0.596 & 0.131 & 0.373 & 0.084 & 0.919 & 0.158 & 0.216 & 0.293 \\
\hline$\ldots \tau_{Q, t} \times$ unskilled & 0.013 & 0.032 & -0.035 & 0.036 & 0.079 & 0.060 & -0.075 & 0.097 \\
\hline$\ldots \tau_{Q, t} \times$ high school & -0.041 & 0.031 & -0.004 & 0.033 & -0.039 & 0.037 & 0.013 & 0.047 \\
\hline$. \tau_{Q, t} \times$ health probl. & 0.052 & 0.044 & 0.090 & 0.049 & -0.077 & 0.090 & 0.089 & 0.108 \\
\hline$\ldots \tau_{Q, t} \times$ age $\geq 50$ & 0.043 & 0.051 & -0.127 & 0.058 & -0.021 & 0.045 & -0.142 & 0.062 \\
\hline \multicolumn{9}{|l|}{$\left[Q_{t-1}=0\right] \times\left[E_{t-1}=0\right] \times \ldots$} \\
\hline$\ldots D_{t}$ & .125 & 0.134 & -0.008 & 0.162 & -0.599 & 0.161 & -0.602 & 0.236 \\
\hline$D_{t} \times(t-s)$ & -0.095 & 0.027 & -0.026 & 0.031 & 0.083 & 0.035 & 0.109 & 0.050 \\
\hline$D_{t} \times(t-s)^{2}$ & 0.008 & 0.002 & 0.004 & 0.002 & -0.003 & 0.002 & -0.001 & 0.003 \\
\hline$D_{t} \times \tau_{Q, t}$ & 0.362 & 0.068 & 0.432 & 0.076 & 0.303 & 0.077 & 0.307 & 0.09 \\
\hline$D_{t} \times \tau_{Q, t}^{2}$ & 0.001 & 0.009 & -0.002 & 0.011 & -0.012 & 0.011 & 0.018 & 0.014 \\
\hline$. D_{t} \times(t-s) \times \tau_{Q}$ & -0.029 & 0.005 & -0.030 & 0.006 & -0.009 & 0.006 & -0.033 & 0.008 \\
\hline
\end{tabular}


Means and Standard deviations of Parameters from MCMC Estimation <continued $>$

\begin{tabular}{|c|c|c|c|c|c|c|c|c|}
\hline Name & Male West & $\begin{array}{l}\text { Jest } \\
\text { SD }\end{array}$ & \multicolumn{2}{|c|}{ Female West } & \multicolumn{2}{|c|}{ Male East } & \multicolumn{2}{|c|}{ Female East } \\
\hline$D_{t} \times$ unskilled & -0.205 & 0.111 & -0.093 & 0.139 & 0.238 & 0.208 & 0.394 & 0.341 \\
\hline$D_{t} \times$ high school & -0.228 & 0.150 & -0.322 & 0.183 & 0.514 & 0.206 & 0.539 & 0.234 \\
\hline$D_{t} \times$ health problems & -0.275 & 0.168 & -0.074 & 0.229 & -0.295 & 0.316 & 0.607 & 0.334 \\
\hline$D_{t} \times$ age $\geq 50$ & 0.099 & 0.177 & 0.004 & 0.191 & -0.283 & 0.192 & -0.616 & 0.262 \\
\hline$\ldots D_{t} \times \tau_{Q, t} \times$ unskilled & 0.035 & 0.045 & 0.011 & 0.054 & -0.078 & 0.080 & -0.293 & 0.131 \\
\hline$\ldots D_{t} \times \tau_{Q, t} \times$ high school & 0.047 & 0.049 & 0.062 & 0.063 & -0.199 & 0.058 & -0.114 & 0.066 \\
\hline$D_{t} \times \tau_{Q, t} \times$ health problems & 0.045 & 0.065 & -0.040 & 0.095 & -0.080 & 0.100 & -0.039 & 0.112 \\
\hline$\ldots D_{t} \times \tau_{Q, t} \times$ age $\geq 50$ & -0.038 & 0.071 & -0.080 & 0.075 & 0.030 & 0.058 & 0.105 & 0.072 \\
\hline \multicolumn{9}{|l|}{$\left[Q_{t-1}=0\right] \times\left[E_{t-1}=1\right] \times \ldots$} \\
\hline$\ldots D_{t}$ & 0.107 & 0.167 & 0.349 & 0.213 & -0.018 & 0.215 & 0.650 & 0.348 \\
\hline$\ldots D_{t} \times(t-s)$ & 0.025 & 0.033 & -0.044 & 0.039 & 0.051 & 0.043 & 0.041 & 0.065 \\
\hline$\ldots D_{t} \times(t-s)^{2}$ & $-0.3^{-4}$ & 0.002 & 0.002 & 0.002 & -0.002 & 0.003 & -0.003 & 0.004 \\
\hline$\ldots D_{t} \times \tau_{Q, t}$ & 0.203 & 0.082 & 0.220 & 0.090 & 0.123 & 0.097 & -0.170 & 0.169 \\
\hline$\ldots D_{t} \times \tau_{Q, t}^{2}$ & -0.011 & 0.011 & -0.004 & 0.011 & 0.001 & 0.013 & 0.040 & 0.026 \\
\hline$\ldots D_{t} \times(t-s) \times \tau_{Q, t}$ & -0.006 & 0.006 & -0.001 & 0.007 & -0.003 & 0.007 & 0.001 & 0.010 \\
\hline$\ldots D_{t} \times$ unskilled & -0.169 & 0.133 & 0.172 & 0.162 & 0.502 & 0.299 & 0.723 & 0.536 \\
\hline$. D_{t} \times$ high school & -0.140 & 0.173 & 0.146 & 0.202 & 0.133 & 0.221 & -0.152 & 0.277 \\
\hline$\ldots D_{t} \times$ health problems & -0.442 & 0.200 & -0.118 & 0.260 & 1.523 & 0.650 & -0.478 & 0.495 \\
\hline$\ldots D_{t} \times$ age $\geq 50$ & -0.692 & 0.226 & -0.166 & 0.215 & -0.255 & 0.234 & -0.316 & 0.342 \\
\hline$\ldots D_{t} \times \tau_{Q, t} \times$ unskilled & 0.006 & 0.055 & -0.081 & 0.062 & -0.146 & 0.114 & -0.288 & 0.205 \\
\hline$\ldots D_{t} \times \tau_{Q, t} \times$ high school & -0.028 & 0.055 & -0.077 & 0.065 & -0.086 & 0.065 & 0.006 & 0.084 \\
\hline$\ldots D_{t} \times \tau_{Q, t} \times$ health prob. & 0.206 & 0.075 & 0.096 & 0.093 & -0.987 & 0.322 & 0.521 & 0.165 \\
\hline$\ldots D_{t} \times \tau_{Q, t} \times$ age $\geq 50$ & 0.206 & 0.094 & 0.022 & 0.084 & 0.058 & 0.083 & 0.094 & 0.108 \\
\hline$\overline{E_{t-1}}$ & 1.913 & 0.129 & 2.027 & 0.152 & 1.721 & 0.204 & 2.342 & 0.280 \\
\hline$E_{t-2}$ & -0.220 & 0.032 & -0.316 & 0.044 & -0.267 & 0.046 & -0.359 & 0.075 \\
\hline$E_{t-3}$ & -0.278 & 0.034 & -0.293 & 0.047 & -0.272 & 0.049 & -0.279 & 0.081 \\
\hline$E_{t-4}$ & 0.425 & 0.014 & 0.277 & 0.021 & 0.268 & 0.021 & 0.290 & 0.035 \\
\hline$\sum_{j=5}^{8} E_{t-j}$ & -0.178 & 0.007 & -0.212 & 0.009 & -0.141 & 0.010 & -0.250 & 0.015 \\
\hline$\sum_{j=9}^{12} E_{t-j}$ & -0.123 & 0.008 & -0.128 & 0.010 & -0.070 & 0.011 & -0.138 & 0.018 \\
\hline$\sum_{j=13}^{16} E_{t-j}$ & -0.220 & 0.012 & -0.229 & 0.017 & -0.197 & 0.018 & -0.284 & 0.031 \\
\hline$t>1$ & 0.327 & 0.022 & 0.396 & 0.028 & 0.348 & 0.031 & 0.430 & 0.048 \\
\hline$t>2$ & 0.041 & 0.021 & 0.078 & 0.026 & 0.046 & 0.030 & 0.091 & 0.046 \\
\hline$t>3$ & -0.154 & 0.021 & -0.052 & 0.027 & -0.114 & 0.030 & -0.146 & 0.047 \\
\hline$t>4$ & 0.286 & 0.021 & 0.233 & 0.027 & 0.294 & 0.030 & 0.297 & 0.048 \\
\hline$t>5$ & 0.035 & 0.020 & 0.076 & 0.025 & 0.004 & 0.028 & 0.120 & 0.044 \\
\hline$t>9$ & 0.207 & 0.019 & 0.192 & 0.025 & 0.187 & 0.027 & 0.231 & 0.042 \\
\hline$t>13$ & 0.244 & 0.021 & 0.200 & 0.026 & 0.164 & 0.030 & 0.246 & 0.045 \\
\hline$E_{t-1} \times t$ & 0.079 & 0.045 & 0.014 & 0.064 & -0.068 & 0.065 & -0.070 & 0.109 \\
\hline$E_{t-2} \times t$ & -0.003 & 0.048 & -0.001 & 0.068 & 0.076 & 0.069 & -0.114 & 0.113 \\
\hline
\end{tabular}


Means and Standard deviations of Parameters from MCMC Estimation < continued $>$

\begin{tabular}{|c|c|c|c|c|c|c|c|c|}
\hline Name & \begin{tabular}{|l} 
Male I \\
Mean
\end{tabular} & $\begin{array}{l}\text { Jest } \\
\text { SD }\end{array}$ & $\begin{array}{l}\text { Female } \\
\text { Mean }\end{array}$ & $\begin{array}{l}\text { West } \\
\text { SD }\end{array}$ & $\begin{array}{l}\text { Male E } \\
\text { Mean }\end{array}$ & $\begin{array}{l}\text { East } \\
\text { SD }\end{array}$ & $\begin{array}{l}\text { Female } \\
\text { Mean }\end{array}$ & $\begin{array}{l}\text { East } \\
\mathrm{SD}\end{array}$ \\
\hline$\overline{E_{t-3} \times t}$ & 0.482 & 0.049 & 0.412 & 0.070 & 0.407 & 0.073 & 0.462 & 0.118 \\
\hline$\tau_{E, t} \times\left[E_{t-1}=0\right]$ & 101 & 0.019 & -0.121 & 0.020 & 0.028 & 0.029 & -0.116 & 0.034 \\
\hline$\tau_{E, t} \times\left[E_{t-1}=1\right]$ & 0.002 & 0.023 & -0.039 & 0.027 & 0.088 & 0.036 & -0.105 & 0.051 \\
\hline$\tau_{E, t}^{2} \times\left[E_{t-1}=0\right]$ & 0.003 & 0.001 & 0.006 & 0.001 & 0.004 & 0.001 & 0.003 & 0.001 \\
\hline$\tau_{E, t}^{2} \times\left[E_{t-1}=1\right]$ & .005 & 0.001 & 0.001 & 0.001 & 0.000 & 0.001 & 0.001 & 0.002 \\
\hline last job: assisting workers & -0.096 & 0.023 & 0.017 & 0.044 & -0.149 & 0.032 & -0.096 & 0.079 \\
\hline last job: jobs in ser & -0.097 & 0.035 & 0.057 & 0.038 & -0.081 & 0.057 & -0.077 & 0.065 \\
\hline last job: office or business job & -0.077 & 0.038 & 0.082 & 0.042 & -0.199 & 0.068 & -0.039 & 0.073 \\
\hline ast job: te & .032 & 0.039 & 0.054 & 0.047 & -0.068 & 0.058 & -0.050 & 0.084 \\
\hline ast job: ac & -0.050 & 0.044 & 0.092 & 0.049 & -0.109 & 0.066 & -0.043 & 0.090 \\
\hline shar & 0.860 & 0.136 & 0.303 & 0.199 & 0.647 & 0.262 & 1.105 & 0.378 \\
\hline log last as & .202 & 0.042 & 0.148 & 0.054 & 0.168 & 0.140 & 0.242 & 0.118 \\
\hline $\log 1$ & 0.017 & 0.006 & -0.007 & 0.008 & 0.022 & 0.020 & -0.009 & 0.017 \\
\hline last & -0.077 & 0.032 & -0.037 & 0.035 & -0.128 & 0.050 & -0.017 & 0.060 \\
\hline ast & 0.198 & 0.031 & 0.215 & 0.038 & 0.202 & 0.040 & 0.305 & 0.062 \\
\hline ast & -0.069 & 0.039 & -0.107 & 0.031 & -0.044 & 0.067 & -0.009 & 0.055 \\
\hline day & 0.125 & 0.014 & 0.128 & 0.019 & 0.061 & 0.021 & 0.085 & 0.034 \\
\hline day & & 0.001 & -0.008 & 0.001 & -0.001 & 0.001 & 05 & 0.002 \\
\hline age/ & -0.650 & 0.136 & 0.846 & 0.183 & -0.720 & 0.187 & -0.571 & 0.327 \\
\hline no $\mathrm{v}$ & -0.104 & 0.021 & 0.072 & 0.028 & -0.014 & 0.042 & -0.220 & 0.071 \\
\hline so & -0.047 & 0.022 & -0.193 & 0.038 & -0.200 & 0.046 & -0.074 & 0.094 \\
\hline gi & -0.275 & 0.034 & -0.039 & 0.036 & -0.147 & 0.054 & -0 & 0.072 \\
\hline อa & -1.467 & 0.039 & -1.280 & 0.051 & -1.328 & 0.069 & -1.825 & 0.133 \\
\hline 1 & 0.084 & 0.014 & 0.259 & 0.019 & -0.050 & 0.020 & -0.044 & 0.032 \\
\hline & -0.042 & 0.069 & 0.094 & 0.100 & -0.379 & 0.053 & 21 & 0.087 \\
\hline urban regi & -0.145 & 0.023 & -0.060 & 0.032 & -0.494 & 0.057 & -1.010 & 0.095 \\
\hline unemploy & -0.001 & 0.002 & $-0.5^{-4}$ & 0.003 & -0.010 & 0.003 & 0.008 & 0.004 \\
\hline wint & .033 & 0.015 & 0.017 & 0.018 & -0.089 & 0.022 & -0.032 & 0.033 \\
\hline & 2 & 0.013 & 0.2 & 0.016 & 0.483 & 0.018 & 0.290 & 0.028 \\
\hline & & $0 .($ & & 0.015 & 0.420 & 0.017 & 0. & 0.026 \\
\hline year & 77 & 0.057 & 0.208 & 0.072 & 0.365 & 0.081 & -0.108 & 0.130 \\
\hline yeal & 31 & 0.044 & 0.1 & 0.056 & 0.257 & 0.063 & 75 & 0.101 \\
\hline year & 211 & 0.033 & 0.120 & 0.042 & 0.120 & 0.048 & -0.069 & 0.075 \\
\hline year & 0.201 & 0.022 & 0.086 & 0.028 & 0.139 & 0.032 & -0.029 & 0.049 \\
\hline $0 \times E_{t-1}$ & -0.591 & 0.158 & -0.994 & 0.212 & 0.023 & 0.230 & -1.512 & 0.383 \\
\hline low skilled $\times E_{t}$ & -0.099 & 0.026 & -0.354 & 0.037 & -0.105 & 0.057 & -0.037 & 0.095 \\
\hline hool (Abitur) $\times E_{t-1}$ & 0.577 & 0.043 & & 0.046 & 0.540 & 0.070 & & 0.090 \\
\hline health problems $\times E_{t-1}$ & -0.076 & 0.054 & -0.190 & 0.073 & 0.033 & 0.099 & -0.001 & 0.199 \\
\hline share last wages censored $\times E_{t-1}$ & -0.201 & 0.158 & -0.828 & 0.219 & -0.925 & 0.225 & -1.709 & 0.386 \\
\hline log last average real wage $\times E_{t-1}$ & -0.147 & 0.028 & -0.091 & 0.030 & -0.166 & 0.045 & -0.158 & 0.061 \\
\hline & -0.282 & 0.022 & -0.055 & 0.024 & -0.213 & 0.033 & -0.021 & 0.042 \\
\hline low skilled $\times \tau_{E, t}$ & -0.003 & 0.004 & -0.014 & 0.004 & -0.015 & 0.008 & -0.008 & 0.01 \\
\hline
\end{tabular}


Means and Standard deviations of Parameters from MCMC Estimation < continued $>$

\begin{tabular}{l|ll|ll|ll|ll|l}
\hline & \multicolumn{2}{|l|}{ Male West } & \multicolumn{2}{|l|}{ Female West } & \multicolumn{2}{|l|}{ Male East } & \multicolumn{2}{|l}{ Female East } \\
Name & Mean & SD & Mean & SD & Mean & SD & Mean & SD \\
\hline high skilled $\times \tau_{E, t}$ & 0.032 & 0.005 & 0.012 & 0.005 & 0.025 & 0.008 & 0.016 & 0.010 \\
health problems $\times \tau_{E, t}$ & 0.043 & 0.007 & 0.015 & 0.008 & 0.038 & 0.011 & 0.066 & 0.016 \\
share last wages censored $\times \tau_{E, t}$ & -0.122 & 0.020 & -0.051 & 0.025 & -0.057 & 0.027 & -0.065 & 0.048 \\
log last average real wage $\times \tau_{E, t}$ & -0.029 & 0.003 & -0.012 & 0.003 & -0.021 & 0.006 & -0.004 & 0.006 \\
age $100 \times \tau_{E, t} \times E_{t-1}$ & 0.274 & 0.034 & 0.245 & 0.040 & 0.128 & 0.050 & 0.262 & 0.077 \\
low skilled $\times \tau_{E, t} \times E_{t-1}$ & 0.027 & 0.006 & 0.043 & 0.007 & 0.054 & 0.013 & 0.009 & 0.020 \\
high school $\left(\right.$ Abitur $\times \tau_{E, t} \times E_{t-1}$ & -0.029 & 0.008 & -0.024 & 0.008 & -0.021 & 0.013 & -0.066 & 0.016 \\
health problems $\times \tau_{E, t} \times E_{t-1}$ & -0.012 & 0.011 & 0.025 & 0.014 & -0.013 & 0.019 & -0.064 & 0.042 \\
share last wages cens. $\times \tau_{E, t} \times E_{t-1}$ & 0.126 & 0.032 & 0.140 & 0.044 & 0.118 & 0.047 & 0.355 & 0.091 \\
log last av. real wage $\times \tau_{E, t} \times E_{t-1}$ & 0.028 & 0.006 & 0.020 & 0.006 & 0.020 & 0.009 & 0.032 & 0.012 \\
constant & -2.667 & 0.141 & -2.665 & 0.180 & -1.900 & 0.304 & -1.393 & 0.340 \\
\hline
\end{tabular}

\begin{tabular}{|c|c|c|c|c|c|c|c|c|}
\hline \multicolumn{9}{|c|}{ Participation Equation } \\
\hline$\overline{\tau_{Q, t}}$ & 0.038 & 0.048 & 0.071 & 0.060 & 0.060 & 0.056 & 0.230 & 0.000 \\
\hline$Q_{t-1}$ & 663 & 0.138 & 0.688 & 0.157 & 0.429 & 0.162 & -0.534 & 0.247 \\
\hline $\mathrm{d}$ end missing & 458 & 0.108 & 0.892 & 0.151 & 1.482 & 0.185 & 0.942 & 0.329 \\
\hline enough dur. left & 52 & 0.061 & 2.009 & 0.070 & 2.206 & 0.075 & 2.523 & 0.100 \\
\hline . & -0.175 & 0.007 & -0.168 & 0.008 & -0.206 & 0.010 & -0.214 & 0.011 \\
\hline 11110 & 0.035 & 0.044 & 0.012 & 0.047 & -0.211 & 0.058 & -0.178 & 0.079 \\
\hline & 061 & 0.014 & -0.036 & 0.016 & 0.092 & 0.019 & 0.046 & 0.021 \\
\hline on sq. & -0.008 & 0.001 & 0.001 & 0.001 & -0.010 & 0.001 & -0.006 & 0.002 \\
\hline & -0.009 & 0.001 & -0.009 & 0.001 & -0.009 & 0.001 & 09 & 0.002 \\
\hline & -0.031 & 0.043 & 0.022 & 0.062 & -0.005 & 0.056 & -0.057 & 0.088 \\
\hline & 206 & 0.032 & 0.301 & 0.037 & 0.254 & 0.041 & 0.339 & 0.051 \\
\hline & 34 & 0.032 & 0.176 & 0.036 & 0.194 & 0.040 & 0.375 & 0.048 \\
\hline & 17 & 0.031 & 0.147 & 0.035 & 0.124 & 0. & 0.207 & 0.050 \\
\hline & 59 & 0. & 0.590 & 0.124 & 0.706 & & 0.415 & 0.187 \\
\hline & 79 & 0.0 & 0.382 & & 0.639 & & 0.452 & 0.173 \\
\hline & & & 32 & & 01 & & 01 & 0.158 \\
\hline & & 0.0 & 0.033 & 0.095 & 0.293 & & 0.029 & 0.152 \\
\hline & & & & & & & -0 & 74 \\
\hline & 22 & 0.1 & -0. & 0.042 & 0.001 & & -0.043 & 0.061 \\
\hline & م م०A & 0.0 & 0.083 & 0.044 & -0.018 & 0.049 & 0.074 & 0.05 \\
\hline & 67 & 0.042 & 0.057 & 0.047 & -0 & 0.050 & -0.015 & 0.064 \\
\hline & & & -0. & & -0. & & -0.079 & 0.06 \\
\hline & 28 & 0. & -0.263 & 0.074 & -0.194 & 0. & 34 & 0.126 \\
\hline & & 0.036 & 0.045 & 0.037 & 0.160 & & 0.036 & 0.05 \\
\hline & & 0. & & & -0.065 & & -0.136 & 0.07 \\
\hline & & 0.046 & & 0.039 & 0.038 & 0.077 & 0.128 & 0.046 \\
\hline & & 0. & & & & 0.069 & 0.159 & 0.06 \\
\hline & & & & & 0.209 & 0.055 & 0.265 & 0.055 \\
\hline & -0.231 & 0.052 & -0.088 & 0.057 & -0.226 & 0.065 & -0.133 & $0.06^{\circ}$ \\
\hline parttıme worker & 0.078 & 0.053 & -0.042 & 0.043 & 0.002 & 0.088 & 0.140 & 0.05 \\
\hline
\end{tabular}


Means and Standard deviations of Parameters from MCMC Estimation <continued $>$

\begin{tabular}{|c|c|c|c|c|c|c|c|c|}
\hline \multirow[b]{2}{*}{ Name } & \multicolumn{2}{|c|}{ Male West } & \multicolumn{2}{|c|}{ Female West } & \multicolumn{2}{|c|}{ Male East } & \multicolumn{2}{|c|}{ Female East } \\
\hline & Mean & $\mathrm{SD}$ & Mean & $\mathrm{SD}$ & Mean & SD & Mean & SD \\
\hline log last average real wage & 0.068 & 0.019 & 0.013 & 0.025 & 0.056 & 0.027 & 0.093 & 0.034 \\
\hline health problems & 112 & 0.039 & 0.201 & 0.050 & -0.067 & 0.061 & 0.051 & 0.075 \\
\hline at least one child & 135 & 0.027 & 0.197 & 0.034 & 0.150 & 0.034 & 0.266 & 0.045 \\
\hline days/91 employed last 3 years & -0.008 & 0.022 & -0.020 & 0.027 & -0.038 & 0.031 & -0.081 & 0.037 \\
\hline ployed last 3 years squ. & .001 & 0.001 & 0.002 & 0.002 & 0.003 & 0.002 & 0.006 & 0.002 \\
\hline pl. compensation & 0.169 & 0.046 & 0.112 & 0.061 & 0.122 & 0.063 & 0.300 & 0.086 \\
\hline e in community & 005 & 0.004 & 0.005 & 0.005 & 0.012 & 0.005 & -0.002 & 0.006 \\
\hline$\times \tau_{Q, t}$ & -0.325 & 0.165 & -0.143 & 0.212 & -0.322 & 0.250 & 0.924 & 0.348 \\
\hline$\times \tau_{Q, t}$ & -0.066 & 0.146 & -0.079 & 0.193 & -0.282 & 0.200 & 0.894 & 0.293 \\
\hline$\times \tau_{Q, t}$ & 0.382 & 0.165 & 0.107 & 0.180 & 0.350 & 0.220 & 0.824 & 0.305 \\
\hline$\times \tau_{Q, t}$ & 0.264 & 0.172 & -0.363 & 0.184 & 0.171 & 0.230 & 0.804 & 0.306 \\
\hline 50 years or 1 & 0.446 & 0.206 & -0.104 & 0.237 & 0.466 & 0.261 & 1.242 & 0.337 \\
\hline no vocat. de & -0.183 & 0.103 & -0.292 & 0.127 & -0.669 & 0.218 & -0.142 & 0.26 \\
\hline$\times Q_{t-1}$ & 0.138 & 0.079 & 0.041 & 0.093 & -0.025 & 0.110 & -0.242 & 0.12 \\
\hline$\times Q_{t-1}$ & 0.053 & 0.060 & 0.068 & 0.085 & 0.002 & 0.079 & -0.172 & 0.10 \\
\hline$\times Q_{t-1}$ & 97 & 0.0 & 75 & 0.079 & -0.167 & 0.084 & -0.203 & 0.112 \\
\hline is old $\times Q_{t-1}$ & -0.033 & 0.072 & 0.099 & 0.077 & -0.143 & 0.088 & -0.192 & 0.110 \\
\hline r more $\times Q_{t-1}$ & -0.116 & 0.103 & -0.059 & 0.121 & -0.229 & 0.097 & -0.318 & 0.117 \\
\hline no vocational degree $\times Q_{t-1}$ & 0.054 & 0.046 & 0.061 & 0.055 & 0.247 & 0.099 & 0.158 & 0.099 \\
\hline constant & -3.477 & 0.186 & -3.223 & 0.219 & -3.483 & 0.261 & -3.424 & 0.306 \\
\hline \multicolumn{9}{|c|}{ Individual Level Variances and Covariances } \\
\hline & 0.617 & 0.028 & 0.880 & 0.047 & 0.553 & 0.039 & 1.047 & 0.087 \\
\hline $\operatorname{Var}\left(\alpha_{Q}\right)$ & 0.286 & 0.065 & 0.451 & 0.089 & 0.356 & 0.073 & 0.292 & 0.072 \\
\hline $\operatorname{Cov}\left(\alpha_{E}, \alpha_{Q}\right)$ & -0.046 & 0.026 & -0.003 & 0.042 & -0.053 & 0.032 & -0.122 & 0.057 \\
\hline $\operatorname{Var}\left(\alpha_{E}\right) /\left(\operatorname{Var}\left(\alpha_{E}\right)+1\right)$ & 0. & 0.0 & & 0.013 & 0.356 & 0.016 & 0.511 & 0.021 \\
\hline $\operatorname{Var}\left(\alpha_{Q}\right) /\left(\operatorname{Var}\left(\alpha_{Q}\right)+1\right)$ & 0.221 & 0.039 & 0.308 & 0.042 & 0.261 & 0.039 & 0.224 & 0.042 \\
\hline $\operatorname{Corr}\left(\alpha_{E}+\epsilon_{E, t}, \alpha_{Q}+\epsilon_{Q, t}\right)$ & -0.032 & 0.018 & -0.002 & 0.025 & -0.036 & 0.021 & -0.075 & 0.03 \\
\hline $\operatorname{Corr}\left(\alpha_{E}, \alpha_{Q}\right)$ & -0.109 & 0.060 & -0.004 & 0.067 & -0.120 & 0.069 & -0.220 & 0.09 \\
\hline
\end{tabular}

Notes: $t=0, \ldots, 16$ indexes the quarters since the inflow. $E_{t}$ indicates the employment status and $Q_{t}$ the training status in period $t . \tau_{E, t}$ and $\tau_{Q, t}$ indicate the elapsed duration in employment/unemployment and training, respectively. $D_{t}$ is a dummy equal to one if a participation in training occurred during any previous quarter since the inflow. $(t-s)$ denotes the elapsed time since the beginning of the program. $\alpha_{E}\left(\alpha_{Q}\right)$ denotes the individual specific effect in the employment (qualification) equation, $\epsilon_{E, t}\left(\epsilon_{Q, t}\right)$ the idiosyncratic error term in the employment (qualification) equation. 
Table 6: Classical ATT Aligned to Program Start

\begin{tabular}{l|ll|ll|ll|ll}
\hline & \multicolumn{2}{|c|}{ Male West } & \multicolumn{2}{|c|}{ Female West } & \multicolumn{2}{c|}{ Male East } & \multicolumn{2}{c}{ Female East } \\
$t-s$ & Mean & SD & Mean & SD & Mean & SD & Mean & SD \\
\hline 0 & -0.134 & 0.009 & -0.106 & 0.009 & -0.139 & 0.010 & -0.073 & 0.010 \\
1 & -0.141 & 0.012 & -0.107 & 0.013 & -0.169 & 0.014 & -0.076 & 0.014 \\
2 & -0.073 & 0.014 & -0.047 & 0.016 & -0.116 & 0.015 & -0.049 & 0.015 \\
3 & -0.002 & 0.014 & 0.040 & 0.018 & -0.051 & 0.016 & -0.010 & 0.017 \\
4 & 0.046 & 0.015 & 0.115 & 0.020 & -0.019 & 0.017 & 0.038 & 0.018 \\
5 & 0.066 & 0.016 & 0.154 & 0.021 & 0.023 & 0.018 & 0.073 & 0.021 \\
6 & 0.084 & 0.017 & 0.173 & 0.022 & 0.060 & 0.019 & 0.106 & 0.022 \\
7 & 0.099 & 0.017 & 0.187 & 0.023 & 0.090 & 0.019 & 0.132 & 0.022 \\
8 & 0.114 & 0.017 & 0.202 & 0.023 & 0.113 & 0.019 & 0.154 & 0.024 \\
9 & 0.119 & 0.018 & 0.210 & 0.023 & 0.133 & 0.021 & 0.170 & 0.025 \\
\hline
\end{tabular}

Notes: $t-s$ denotes the quarters elapsed since program start.

Table 7: Predicted Participation Rate of Participants if Postponing Participation (Aligned to Start of Program)

\begin{tabular}{l|ll|ll|ll|ll}
\hline & \multicolumn{2}{|c|}{ Male West } & \multicolumn{2}{c|}{ Female West } & \multicolumn{2}{c|}{ Male East } & \multicolumn{2}{c}{ Female East } \\
$t-s$ & $\hat{Q}_{t-s}$ & $\bar{Q}_{t-s}$ & $\hat{Q}_{t-s}$ & $\bar{Q}_{t-s}$ & $\hat{Q}_{t-s}$ & $\bar{Q}_{t-s}$ & $\hat{Q}_{t-s}$ & $\bar{Q}_{t-s}$ \\
\hline 0 & 0.000 & 1.000 & 0.000 & 1.000 & 0.000 & 1.000 & 0.000 & 1.000 \\
1 & 0.270 & 0.650 & 0.175 & 0.708 & 0.337 & 0.729 & 0.220 & 0.742 \\
2 & 0.317 & 0.413 & 0.192 & 0.464 & 0.374 & 0.533 & 0.221 & 0.619 \\
3 & 0.292 & 0.226 & 0.165 & 0.229 & 0.333 & 0.349 & 0.189 & 0.432 \\
4 & 0.241 & 0.074 & 0.132 & 0.064 & 0.269 & 0.142 & 0.151 & 0.195 \\
5 & 0.177 & 0.020 & 0.095 & 0.025 & 0.197 & 0.024 & 0.107 & 0.029 \\
6 & 0.132 & 0.020 & 0.072 & 0.021 & 0.141 & 0.014 & 0.073 & 0.021 \\
7 & 0.099 & 0.019 & 0.053 & 0.018 & 0.097 & 0.010 & 0.052 & 0.018 \\
8 & 0.078 & 0.006 & 0.043 & 0.011 & 0.071 & 0.006 & 0.039 & 0.012 \\
9 & 0.060 & 0.001 & 0.035 & 0.008 & 0.050 & 0.000 & 0.028 & 0.002 \\
Total & 0.687 & 1 & 0.523 & 1 & 0.767 & 1 & 0.626 & 1 \\
\hline
\end{tabular}

Notes: $t-s$ denotes the quarters elapsed since program start. $\bar{Q}_{t-s}$ is the mean of the participation dummy of participants as observed in data, $\hat{Q}_{t-s}$ the mean as predicted under the waiting scenario. The row labeled "Total" gives the share of those who ever enrol into a program. 
Table 8: ATT of Training versus Waiting Aligned to Program Start

\begin{tabular}{l|ll|ll|ll|ll}
\hline & \multicolumn{2}{|c|}{ Male West } & \multicolumn{2}{|c|}{ Female West } & \multicolumn{2}{c|}{ Male East } & \multicolumn{2}{c}{ Female East } \\
$t-s$ & Mean & SD & Mean & SD & Mean & SD & Mean & SD \\
\hline 0 & -0.134 & 0.009 & -0.106 & 0.009 & -0.139 & 0.010 & -0.073 & 0.010 \\
1 & -0.141 & 0.012 & -0.107 & 0.014 & -0.169 & 0.014 & -0.076 & 0.014 \\
2 & -0.058 & 0.013 & -0.041 & 0.015 & -0.090 & 0.015 & -0.044 & 0.015 \\
3 & 0.014 & 0.012 & 0.044 & 0.016 & -0.020 & 0.014 & -0.003 & 0.015 \\
4 & 0.051 & 0.012 & 0.108 & 0.017 & 0.007 & 0.014 & 0.042 & 0.015 \\
5 & 0.051 & 0.012 & 0.130 & 0.018 & 0.039 & 0.013 & 0.070 & 0.017 \\
6 & 0.058 & 0.013 & 0.138 & 0.019 & 0.062 & 0.014 & 0.094 & 0.018 \\
7 & 0.062 & 0.013 & 0.141 & 0.019 & 0.068 & 0.016 & 0.111 & 0.020 \\
8 & 0.068 & 0.013 & 0.147 & 0.020 & 0.076 & 0.016 & 0.124 & 0.022 \\
9 & 0.065 & 0.013 & 0.148 & 0.020 & 0.080 & 0.018 & 0.129 & 0.025 \\
\hline
\end{tabular}

Notes: $t-s$ denotes the quarters elapsed since program start.

Table 9: Predicted Participation and Employment Rates for Different Planned Program Durations: Male, West

\begin{tabular}{l|ll|ll|ll|ll}
\hline & \multicolumn{2}{|c|}{ One quarter } & \multicolumn{2}{c|}{ Two quarters } & \multicolumn{2}{c|}{ Three quarters } & \multicolumn{2}{c}{ Four quarters } \\
$t-s$ & $\hat{Q}_{t-s}$ & $\hat{E}_{t-s}$ & $\hat{Q}_{t-s}$ & $\hat{E}_{t-s}$ & $\hat{Q}_{t-s}$ & $\hat{E}_{t-s}$ & $\hat{Q}_{t-s}$ & $\hat{E}_{t-s}$ \\
\hline 0 & 1.000 & 0.000 & 1.000 & 0.000 & 1.000 & 0.000 & 1.000 & 0.000 \\
1 & 0.399 & 0.079 & 0.793 & 0.079 & 0.904 & 0.079 & 0.918 & 0.079 \\
2 & 0.086 & 0.187 & 0.286 & 0.165 & 0.706 & 0.159 & 0.812 & 0.158 \\
3 & 0.024 & 0.246 & 0.061 & 0.244 & 0.246 & 0.232 & 0.617 & 0.229 \\
4 & 0.007 & 0.267 & 0.017 & 0.290 & 0.050 & 0.311 & 0.198 & 0.326 \\
5 & 0.003 & 0.296 & 0.006 & 0.329 & 0.015 & 0.365 & 0.043 & 0.387 \\
6 & 0.001 & 0.316 & 0.002 & 0.348 & 0.005 & 0.390 & 0.013 & 0.422 \\
7 & 0.001 & 0.323 & 0.001 & 0.358 & 0.002 & 0.399 & 0.005 & 0.435 \\
8 & 0.000 & 0.328 & 0.001 & 0.365 & 0.001 & 0.410 & 0.003 & 0.448 \\
9 & 0.000 & 0.344 & 0.000 & 0.383 & 0.001 & 0.429 & 0.001 & 0.467 \\
\hline
\end{tabular}

Notes: $t-s$ denotes the quarters elapsed since program start. $\hat{Q}_{t-s}$ and $\hat{E}_{t-s}$ are the simulated means of the participation and employment probability, respectively. 
Table 10: Predicted Participation and Employment Rates for Different Planned Program Durations: Female, West

\begin{tabular}{l|ll|ll|ll|ll}
\hline & \multicolumn{2}{|c|}{ One quarter } & \multicolumn{2}{c|}{ Two quarters } & \multicolumn{2}{c|}{ Three quarters } & \multicolumn{2}{c}{ Four quarters } \\
$t-s$ & $\hat{Q}_{t-s}$ & $\hat{E}_{t-s}$ & $\hat{Q}_{t-s}$ & $\hat{E}_{t-s}$ & $\hat{Q}_{t-s}$ & $\hat{E}_{t-s}$ & $\hat{Q}_{t-s}$ & $\hat{E}_{t-s}$ \\
\hline 0 & 1.000 & 0.000 & 1.000 & 0.000 & 1.000 & 0.000 & 1.000 & 0.000 \\
1 & 0.416 & 0.070 & 0.825 & 0.070 & 0.922 & 0.070 & 0.931 & 0.070 \\
2 & 0.099 & 0.166 & 0.311 & 0.151 & 0.748 & 0.147 & 0.836 & 0.147 \\
3 & 0.030 & 0.246 & 0.071 & 0.253 & 0.269 & 0.249 & 0.647 & 0.248 \\
4 & 0.011 & 0.292 & 0.021 & 0.325 & 0.059 & 0.357 & 0.219 & 0.377 \\
5 & 0.005 & 0.328 & 0.008 & 0.372 & 0.019 & 0.422 & 0.051 & 0.452 \\
6 & 0.002 & 0.350 & 0.004 & 0.398 & 0.007 & 0.456 & 0.016 & 0.501 \\
7 & 0.001 & 0.364 & 0.002 & 0.415 & 0.004 & 0.475 & 0.007 & 0.524 \\
8 & 0.001 & 0.375 & 0.001 & 0.428 & 0.002 & 0.490 & 0.005 & 0.540 \\
9 & 0.001 & 0.386 & 0.001 & 0.440 & 0.002 & 0.501 & 0.003 & 0.552 \\
\hline
\end{tabular}

Notes: $t-s$ denotes the quarters elapsed since program start. $\hat{Q}_{t-s}$ and $\hat{E}_{t-s}$ are the simulated means of the participation and employment probability, respectively.

Table 11: Predicted Participation and Employment Rates for Different Planned Program Durations: Male, East

\begin{tabular}{l|ll|ll|ll|ll}
\hline & \multicolumn{2}{|c|}{ One quarter } & \multicolumn{2}{c|}{ Two quarters } & \multicolumn{2}{c|}{ Three quarters } & \multicolumn{2}{c}{ Four quarters } \\
$t-s$ & $\hat{Q}_{t-s}$ & $\hat{E}_{t-s}$ & $\hat{Q}_{t-s}$ & $\hat{E}_{t-s}$ & $\hat{Q}_{t-s}$ & $\hat{E}_{t-s}$ & $\hat{Q}_{t-s}$ & $\hat{E}_{t-s}$ \\
\hline 0 & 1.000 & 0.000 & 1.000 & 0.000 & 1.000 & 0.000 & 1.000 & 0.000 \\
1 & 0.455 & 0.048 & 0.869 & 0.048 & 0.946 & 0.048 & 0.952 & 0.048 \\
2 & 0.096 & 0.127 & 0.333 & 0.117 & 0.798 & 0.115 & 0.873 & 0.115 \\
3 & 0.027 & 0.178 & 0.068 & 0.177 & 0.295 & 0.171 & 0.723 & 0.171 \\
4 & 0.009 & 0.214 & 0.020 & 0.227 & 0.062 & 0.229 & 0.264 & 0.215 \\
5 & 0.004 & 0.256 & 0.007 & 0.279 & 0.018 & 0.296 & 0.052 & 0.294 \\
6 & 0.001 & 0.281 & 0.003 & 0.308 & 0.006 & 0.336 & 0.013 & 0.353 \\
7 & 0.001 & 0.291 & 0.001 & 0.321 & 0.003 & 0.352 & 0.006 & 0.374 \\
8 & 0.000 & 0.308 & 0.001 & 0.341 & 0.001 & 0.374 & 0.003 & 0.398 \\
9 & 0.000 & 0.339 & 0.000 & 0.373 & 0.001 & 0.408 & 0.001 & 0.434 \\
\hline
\end{tabular}

Notes: $t-s$ denotes the quarters elapsed since program start. $\hat{Q}_{t-s}$ and $\hat{E}_{t-s}$ are the simulated means of the participation and employment probability, respectively. 
Table 12: Predicted Participation and Employment Rates for Different Planned Program Durations: Female, East

\begin{tabular}{l|ll|ll|ll|ll}
\hline & \multicolumn{2}{|c|}{ One quarter } & \multicolumn{2}{c|}{ Two quarters } & \multicolumn{2}{c|}{ Three quarters } & \multicolumn{2}{c}{ Four quarters } \\
$t-s$ & $\hat{Q}_{t-s}$ & $\hat{E}_{t-s}$ & $\hat{Q}_{t-s}$ & $\hat{E}_{t-s}$ & $\hat{Q}_{t-s}$ & $\hat{E}_{t-s}$ & $\hat{Q}_{t-s}$ & $\hat{E}_{t-s}$ \\
\hline 0 & 1.000 & 0.000 & 1.000 & 0.000 & 1.000 & 0.000 & 1.000 & 0.000 \\
1 & 0.443 & 0.039 & 0.899 & 0.039 & 0.959 & 0.039 & 0.961 & 0.039 \\
2 & 0.075 & 0.083 & 0.352 & 0.076 & 0.866 & 0.074 & 0.919 & 0.074 \\
3 & 0.019 & 0.123 & 0.062 & 0.123 & 0.345 & 0.119 & 0.823 & 0.119 \\
4 & 0.006 & 0.159 & 0.016 & 0.175 & 0.064 & 0.191 & 0.323 & 0.198 \\
5 & 0.002 & 0.195 & 0.006 & 0.219 & 0.018 & 0.249 & 0.064 & 0.260 \\
6 & 0.001 & 0.217 & 0.002 & 0.242 & 0.007 & 0.279 & 0.019 & 0.309 \\
7 & 0.001 & 0.237 & 0.001 & 0.263 & 0.003 & 0.302 & 0.008 & 0.340 \\
8 & 0.000 & 0.263 & 0.001 & 0.290 & 0.002 & 0.330 & 0.005 & 0.373 \\
9 & 0.000 & 0.287 & 0.001 & 0.314 & 0.002 & 0.354 & 0.003 & 0.398 \\
\hline
\end{tabular}

Notes: $t-s$ denotes the quarters elapsed since program start. $\hat{Q}_{t-s}$ and $\hat{E}_{t-s}$ are the simulated means of the participation and employment probability, respectively.

Table 13: ATT of Planned Program Duration of One Quarter versus Two Quarters

\begin{tabular}{l|ll|ll|ll|ll}
\hline & \multicolumn{2}{|c|}{ Male West } & \multicolumn{2}{|c|}{ Female West } & \multicolumn{2}{c|}{ Male East } & \multicolumn{2}{c}{ Female East } \\
$t-s$ & Mean & SD & Mean & SD & Mean & SD & Mean & SD \\
\hline 0 & 0.000 & 0.000 & 0.000 & 0.000 & 0.000 & 0.000 & 0.000 & 0.000 \\
1 & 0.000 & 0.000 & 0.000 & 0.000 & 0.000 & 0.000 & 0.000 & 0.000 \\
2 & 0.022 & 0.006 & 0.016 & 0.006 & 0.011 & 0.006 & 0.007 & 0.007 \\
3 & 0.002 & 0.006 & -0.007 & 0.007 & 0.001 & 0.007 & -0.000 & 0.008 \\
4 & -0.023 & 0.007 & -0.033 & 0.008 & -0.013 & 0.007 & -0.016 & 0.009 \\
5 & -0.033 & 0.007 & -0.045 & 0.008 & -0.023 & 0.008 & -0.024 & 0.010 \\
6 & -0.033 & 0.007 & -0.049 & 0.009 & -0.027 & 0.008 & -0.025 & 0.011 \\
7 & -0.034 & 0.007 & -0.051 & 0.009 & -0.030 & 0.009 & -0.026 & 0.011 \\
8 & -0.037 & 0.007 & -0.053 & 0.009 & -0.033 & 0.009 & -0.027 & 0.011 \\
9 & -0.039 & 0.008 & -0.054 & 0.009 & -0.035 & 0.009 & -0.026 & 0.012 \\
\hline
\end{tabular}

Notes: $t-s$ denotes the quarters elapsed since program start. 
Table 14: ATT of Planned Program Duration of Three Quarters versus Two Quarters

\begin{tabular}{l|ll|ll|ll|ll}
\hline & \multicolumn{2}{|c|}{ Male West } & \multicolumn{2}{c|}{ Female West } & \multicolumn{2}{c|}{ Male East } & \multicolumn{2}{c}{ Female East } \\
$t-s$ & Mean & SD & Mean & SD & Mean & SD & Mean & SD \\
\hline 0 & 0.000 & 0.000 & 0.000 & 0.000 & 0.000 & 0.000 & 0.000 & 0.000 \\
1 & 0.000 & 0.000 & 0.000 & 0.000 & 0.000 & 0.000 & 0.000 & 0.000 \\
2 & -0.006 & 0.002 & -0.003 & 0.002 & -0.002 & 0.002 & -0.001 & 0.002 \\
3 & -0.012 & 0.006 & -0.004 & 0.007 & -0.006 & 0.006 & -0.004 & 0.008 \\
4 & 0.021 & 0.007 & 0.031 & 0.009 & 0.001 & 0.007 & 0.016 & 0.009 \\
5 & 0.037 & 0.008 & 0.049 & 0.009 & 0.017 & 0.007 & 0.030 & 0.010 \\
6 & 0.042 & 0.008 & 0.058 & 0.010 & 0.028 & 0.008 & 0.037 & 0.011 \\
7 & 0.042 & 0.008 & 0.060 & 0.010 & 0.030 & 0.008 & 0.039 & 0.011 \\
8 & 0.044 & 0.008 & 0.061 & 0.010 & 0.033 & 0.009 & 0.040 & 0.011 \\
9 & 0.046 & 0.008 & 0.062 & 0.010 & 0.035 & 0.009 & 0.040 & 0.012 \\
\hline
\end{tabular}

Notes: $t-s$ denotes the quarters elapsed since program start.

Table 15: ATT of Planned Program Duration of Four Quarters versus Two Quarters

\begin{tabular}{l|ll|ll|ll|ll}
\hline & \multicolumn{2}{|c|}{ Male West } & \multicolumn{2}{|c|}{ Female West } & \multicolumn{2}{c|}{ Male East } & \multicolumn{2}{c}{ Female East } \\
$t-s$ & Mean & SD & Mean & SD & Mean & SD & Mean & SD \\
\hline 0 & 0.000 & 0.000 & 0.000 & 0.000 & 0.000 & 0.000 & 0.000 & 0.000 \\
1 & 0.000 & 0.000 & 0.000 & 0.000 & 0.000 & 0.000 & 0.000 & 0.000 \\
2 & -0.007 & 0.002 & -0.004 & 0.002 & -0.002 & 0.002 & -0.001 & 0.002 \\
3 & -0.015 & 0.008 & -0.005 & 0.008 & -0.006 & 0.007 & -0.004 & 0.008 \\
4 & 0.036 & 0.013 & 0.052 & 0.015 & -0.012 & 0.012 & 0.023 & 0.016 \\
5 & 0.059 & 0.012 & 0.080 & 0.015 & 0.014 & 0.012 & 0.041 & 0.016 \\
6 & 0.074 & 0.012 & 0.103 & 0.015 & 0.045 & 0.013 & 0.067 & 0.017 \\
7 & 0.078 & 0.013 & 0.109 & 0.015 & 0.052 & 0.013 & 0.077 & 0.018 \\
8 & 0.082 & 0.013 & 0.111 & 0.016 & 0.057 & 0.014 & 0.083 & 0.019 \\
9 & 0.084 & 0.013 & 0.112 & 0.016 & 0.060 & 0.014 & 0.084 & 0.020 \\
\hline
\end{tabular}

Notes: $t-s$ denotes the quarters elapsed since program start. 